\author{
Parikshit S. Sarda \\ pss0007@mix.wvu.edu
}

Follow this and additional works at: https://researchrepository.wvu.edu/etd

Part of the Chemical Engineering Commons

\footnotetext{
Recommended Citation

Sarda, Parikshit S., "Development of a Dynamic Model and Control System for Load-Following Operation of Supercritical Pulverized Coal Power Plants" (2019). Graduate Theses, Dissertations, and Problem Reports. 4044.

https://researchrepository.wvu.edu/etd/4044

This Thesis is protected by copyright and/or related rights. It has been brought to you by the The Research Repository @ WVU with permission from the rights-holder(s). You are free to use this Thesis in any way that is permitted by the copyright and related rights legislation that applies to your use. For other uses you must obtain permission from the rights-holder(s) directly, unless additional rights are indicated by a Creative Commons license in the record and/ or on the work itself. This Thesis has been accepted for inclusion in WVU Graduate Theses, Dissertations, and Problem Reports collection by an authorized administrator of The Research Repository @ WVU. For more information, please contact researchrepository@mail.wvu.edu.
} 


\title{
Development of a Dynamic Model and Control System for Load-Following Operation of Supercritical Pulverized Coal Power Plants
}

\author{
Parikshit Sanjay Sarda \\ Thesis submitted to the \\ Benjamin M. Statler College of Engineering and Mineral Resources \\ at West Virginia University \\ in partial fulfillment of the requirements \\ for the degree of
}

Masters of Science

In

Chemical Engineering

Debangsu Bhattacharyya, Ph.D., Chair

Fernando Lima, Ph.D.

Stephen Zitney, Ph.D.

Department of Chemical and Biomedical Engineering

Morgantown, West Virginia

2019

Keywords: Load Following, Feed Water Heater, Dynamic Modeling, Control System, Main Steam Temperature

Copyright 2019 Parikshit Sanjay Sarda 


\title{
Abstract \\ Development of a Dynamic Model and Control System for Load-Following Operation of Supercritical Pulverized Coal Power Plants
}

\author{
Parikshit Sanjay Sarda
}

Thermal power plants that have been designed to operate at their rated capacity are being forced to cycle their load and operate under low-load condition to meet changing load demands due to the increased penetration of renewables into the electric grid. The rapid load-following operation is leading to challenging control problems. The goal of this research is to develop dynamic model and control system for efficient load-following operation. The focus of this work is on supercritical pulverized coal (SCPC) power plants. The steady-state model is developed using Aspen Plus and Aspen Custom Modeler and then converted to a pressure-driven Aspen Plus Dynamics model, where the regulatory control layer and coordinated control system (CCS) are developed for efficient servo control and disturbance rejection characteristics. A detailed threeregion dynamic model of the feed water heater is also developed. The model can estimate the changing size of desuperheating, condensing and subcooling zones during load-following. As key components of CCS, control strategies for the coal flow, air flow, boiler feedwater flowrate and reheat steam temperature are developed. The control strategy for the main steam temperature control is developed with due consideration of the time delay of the SCPC system. 


\section{Dedicated to}

My parents and their unconditional love 


\section{Acknowledgement}

I would like to thank everyone who made my masters studies at West Virginia University a fantastic experience that I will never forget.

First, I would like to thank my advisor Dr. Debangsu Bhattacharyya for the opportunity to extend my education to master's studies in his research group. His expertise, patience, and steadfast assistance helped me to guide my development as a student and a researcher. I also extend my deepest gratitude to Dr. Fernando Lima and Dr. Stephen Zitney for being a part of my M.S. committee and giving me new perspectives to learn from. I would also like to thank my colleague Elijah Hedrick and Kathrine Reynolds for their support and contribution for my master's studies.

I would also like to express my gratitude to Dr. Charter Stinespring for giving me academic advice and to all the researchers working in Dr. Bhattacharyya's lab for their valuable inputs throughout my master's course.

Finally, and most importantly, I thank my family and friends for embedding the importance of education in me and their constant coaching and support in my life. 


\section{Table of Contents}

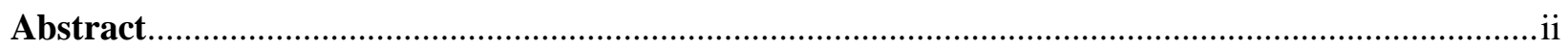

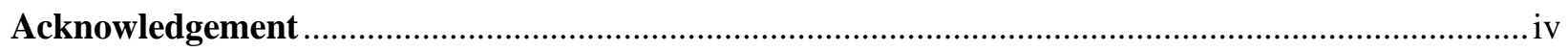

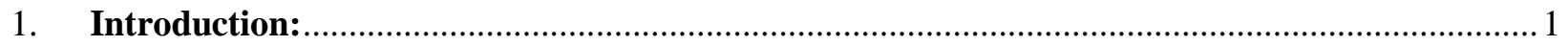

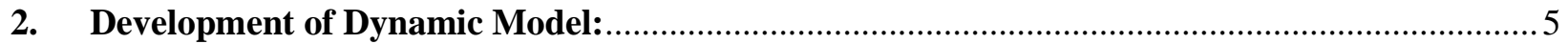

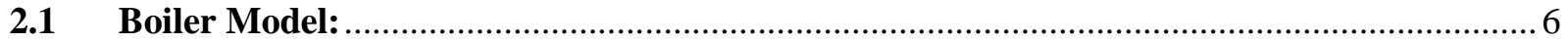

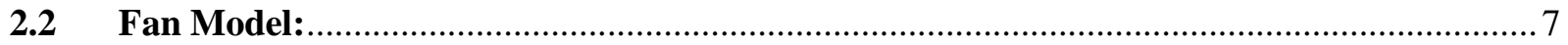

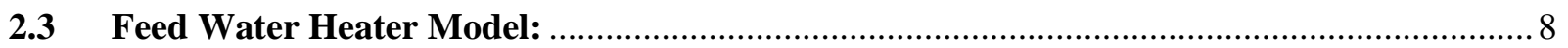

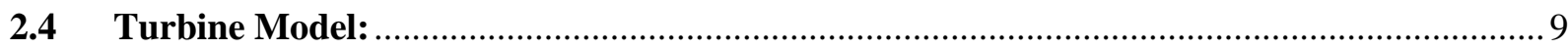

$2.5 \quad$ Integration:

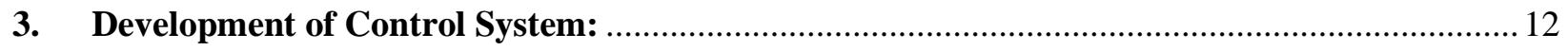

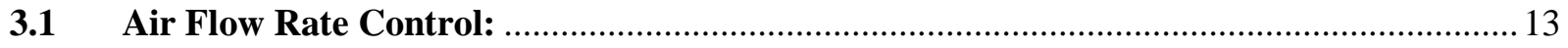

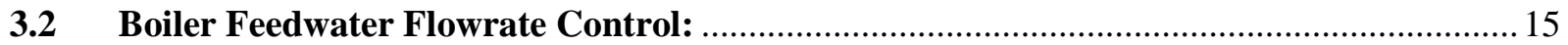

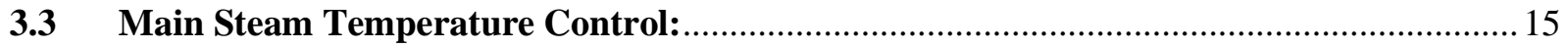

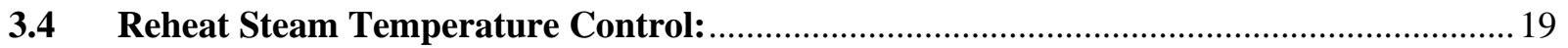

4. Development and design validation of FWH model: .............................................................21

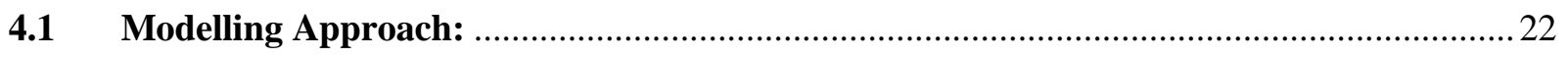

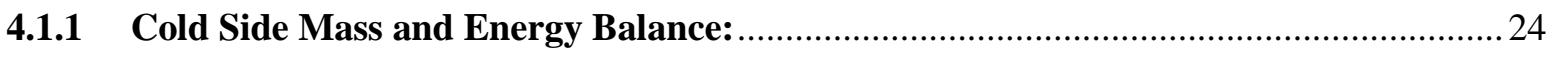

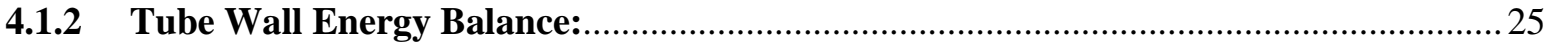

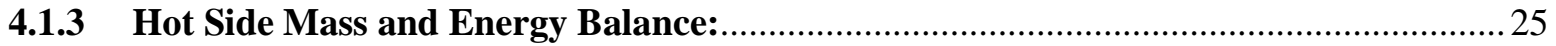

4.1.4 Heat Transfer Coefficient Calculations: .................................................................28

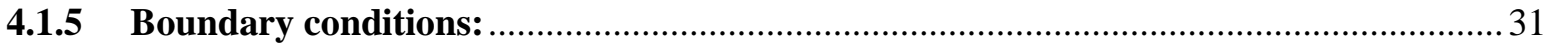

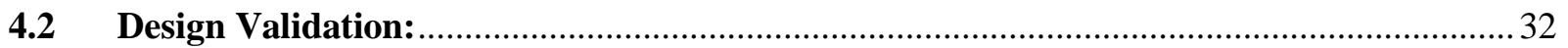

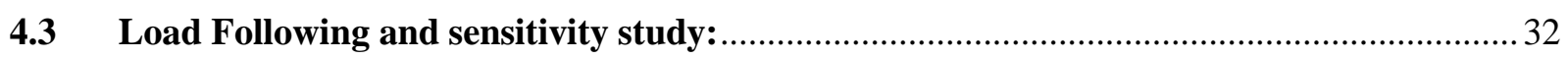

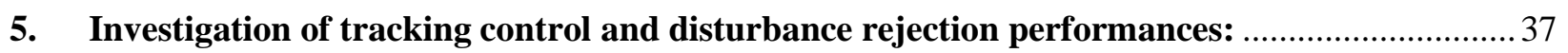

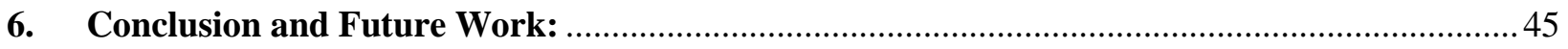

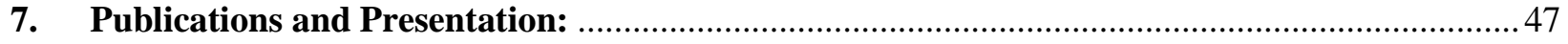

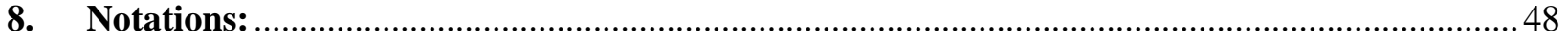

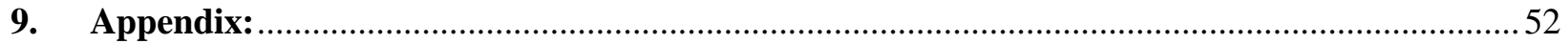

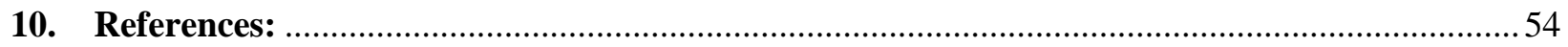




\section{List of Figures}

\begin{tabular}{|c|c|c|}
\hline $\begin{array}{l}\text { Figure } \\
\text { No. }\end{array}$ & Figure Caption & Page No. \\
\hline 1 & SCPC Power Plant Block Flow Diagram & 5 \\
\hline 2 & Schematic of Boiler Model & 7 \\
\hline 3 & Feedwater Pretreatment and Heating Section Block Flow Diagram & 8 \\
\hline 4 & Turbine Section Block Flow Diagram & 10 \\
\hline 5 & Coordinated Control System (CCS) Supervisory Layer & 13 \\
\hline 6 & FD Fan Air Control Scheme & 14 \\
\hline 7 & PA Fan Air Control Scheme & 14 \\
\hline 8 & Boiler Feedwater Flow Control Scheme & 15 \\
\hline 9 & Schematic of High-Pressure Steam Attemperation & 16 \\
\hline 10 & Configuration 1 Control Scheme for Final Steam Temperature & 17 \\
\hline 11 & Configuration 2 Control Scheme for Final Steam Temperature & 17 \\
\hline 12 & Configuration 3 Control Scheme for Final Steam Temperature & 18 \\
\hline 13 & Schematic of Reheat Steam Temperature Control & 19 \\
\hline 14 & $\begin{array}{l}\text { Control Scheme for Primary Control for maintaining Reheat Steam } \\
\text { Temperature }\end{array}$ & 20 \\
\hline 15 & $\begin{array}{l}\text { Control Scheme for Secondary Control for maintaining Reheat Steam } \\
\text { Temperature }\end{array}$ & 20 \\
\hline 16 & Schematic of Feed Water Heater & 21 \\
\hline 17 & Discretization in Feed Water Heater & 22 \\
\hline 18 & Heat Transfer Mechanisms in the FWHs & 24 \\
\hline 19 & Cold Side Flow Pattern & 24 \\
\hline 20 & Effect of Load Following on FWH Duty & 34 \\
\hline 21 & Effect of extraction steam temperature on extraction steam flowrate & 35 \\
\hline 22 & $\begin{array}{l}\text { Effect of extraction steam temperature on cold side outlet temperature } \\
\text { and heat duty }\end{array}$ & 35 \\
\hline 23 & Effect of extraction steam pressure on extraction steam flowrate & 36 \\
\hline 24 & $\begin{array}{l}\text { Effect of extraction steam pressure on cold side outlet temperature and } \\
\text { heat duty }\end{array}$ & 37 \\
\hline 25 & $\begin{array}{l}\text { Response of BFW Flowrate and Main Steam Pressure to a } 60 \% \text { Reduction } \\
\text { in Load }\end{array}$ & 38 \\
\hline 26 & Transients of Main Steam Temperature for Different Control Strategies & 39 \\
\hline 27 & Transients of Attemperator 2 flowrate for configuration 3 & 40 \\
\hline 28 & Response of Reheat Temperature for Different Control Strategies & 41 \\
\hline 29 & Damper performance for Reheat Steam Temperature Control & 41 \\
\hline
\end{tabular}




\begin{tabular}{|c|l|c|}
\hline 30 & $\begin{array}{l}\text { Response of the Boiler Outlet Oxygen Mole Fraction to a 60\% Reduction } \\
\text { in Load }\end{array}$ & 42 \\
\hline 31 & Disturbance Rejection Results for Load and Coal Flow & 43 \\
\hline 32 & Disturbance Rejection Results for Main Steam Temperature & 44 \\
\hline 33 & Disturbance Rejection Results for Oxygen Concentration & 45 \\
\hline 34 & Response of FD Fan Air Flowrate to maintain Oxygen Concentration & 45 \\
\hline
\end{tabular}




\section{List of Tables}

\begin{tabular}{|c|c|c|}
\hline Table No. & Table Caption & Page No. \\
\hline 1 & Steady State Validation & 10 \\
\hline 2 & Heat Transfer Coefficient for water flowing inside tube & 27 \\
\hline 3 & $\begin{array}{l}\text { Heat Transfer Coefficient for desuperheating steam around tube } \\
\text { bundle }\end{array}$ & 28 \\
\hline 4 & Heat Transfer Coefficient for condensation around tube bundle & 29 \\
\hline 5 & $\begin{array}{l}\text { Heat Transfer Coefficient for subcooling liquid around tube } \\
\text { bundle }\end{array}$ & 30 \\
\hline 6 & Boundary condition for overall heat transfer & 30 \\
\hline 7 & Operating condition during Load Following & 32 \\
\hline 8 & $\begin{array}{l}\text { Comparison of Coal Compositions for Disturbance Rejection } \\
\text { Study. }\end{array}$ & 42 \\
\hline 9 & Notation used in FWH Modelling & 49 \\
\hline
\end{tabular}




\section{Introduction:}

Supercritical pulverized coal (SCPC) power plants that have been designed to operate at their rated capacity are being forced to cycle their load and operate under low-load condition to meet changing load demands due to the increased penetration of renewables into the electric grid. Because these plants were not designed for frequent cycling and sustained low-load operation, it leads to considerable loss of efficiency during load following and part load operation. Apart from loss in efficiency, load following and part load operation also adversely impacts plant health and causes increased emissions. To reduce the undesired effects of load-following and part-load operation, improved control strategies can be helpful for maintaining key controlled variables in their desired range. For developing improved controllers and studying their performance, a dynamic model of the plant is necessary. Since the model needs to run reasonably fast and achieve desired accuracy, the trade-off between model fidelity and computational expense is an important consideration. Thermal power plants are highly integrated system and poses serious challenge for modelling and control. For SCPC plants, an additional difficulty that needs to be considered is the high degree of nonlinearity in steam properties, especially when the plant transitions between the supercritical and subcritical regimes during load-following.

While there is a large body of literature on dynamic modeling and control of subcritical pulverized coal plants, there are fewer studies on SCPC plants. In existing literature on dynamic modelling of SCPC plants, works have been reported on model development for individual equipment items as well as for the entire plant. The key components that affect the dynamics under load-following operation are those in the boiler section, steam turbine (ST) section, and feedwater heater $(\mathrm{FWH})$ section.

The boiler plays a critical role in the transient response of the power plants. To study the impact of load following, nonlinear models for separation drum and vertical tubes were integrated and a dynamic model of a subcritical natural circulation boiler was developed (Marchetti et al., 1999). In another work, heat and mass transport characteristics of a supercritical boiler was captured using a "non-equal fragmented model" (Wang et al., 2015). A model for calculating the heat flux distribution and 3-D temperature distribution in a supercritical boiler has been reported (Shu et al., 2013). All these studies only focused on standalone water wall section. Due to the pathways of the flue gas and the BFW/steam, all boiler components like the economizer, 
superheaters, attemperator and the reheater and some upstream components such as the FWHs and downstream components such as the ST should be simulated together. For studying start-up and dynamic behavior, a dynamic model of a $600 \mathrm{MW}$ supercritical plant was developed and used (Deng et al., 2017). This model also included the other components like economizer, superheater, water circulation pump, and water storage tank. The air flow rate was assumed to be sufficient for complete combustion.

The FWHs are part of regenerative heating in Rankine cycle of power plant and it plays a key role in achieving high plant efficiency. An optimal configuration of the FWH network was proposed by consideration of only high-pressure FWHs for increasing the plant efficiency (Devandiran et al., 2016). A nonlinear correlation among the key performance indicator of FWHs like terminal temperature difference, drain cooler approach, and temperature rise was developed as a function of load (Almedilla et al., 2018). In this work, the extraction flow rate was considered to be self-regulating. In another study, optimization of the heat transfer in the FWHs and exhaust flue gas heat recovery system of SCPC plants was proposed to increase plant efficiency and reduce $\mathrm{CO}_{2}$ emissions (Espatolero et al., 2014). That work was based on the assumptions of constant pressure ratio in turbine stages, constant turbine efficiency, constant drain cooling approach, and constant temperature rise. It should be noted that under sliding pressure operation during loadfollowing, extraction pressure can change considerably leading to control limitations and changes in the condensation temperature of steam, which, in turn, affects the dynamics of other sections. Another limitation in the existing literature on the FWH models is that most of them are steadystate models; there is hardly any work which can capture the dynamics of the FWH network as part of the plant-wide model. However, the extraction steam flow to the FWHs are not controlled and therefore the amount of extraction steam depends on the amount of steam that gets condensed in the FWHs since no live steam can leave the FWHs. Furthermore, the most FWHs comprise of desuperheating, condensing, and subccoling zones. While the heat exchanger area under subcooling is rather fixed for a given level due to the mechanical construction of the FWHs, the size of the desuperheating and condensation zone can vary dynamically as the plant follows the load. This varying size of the desuperheating/condensation zone does affect the amount of steam that gets condensed. If the level varies beyond some ranges, the size of the subcooling zone can also vary thus affecting the size of all three zones. Furthermore, some FWHs receive drain cooling liquid from one or more FWHs. Since the FWHs heaters from which drain cooling liquid is sent 
to another FWH operates at a higher temperature and pressure than the destination FWH, the condensate flashes generating steam that also gets condensed along with the extraction steam. Therefore the dynamics of these FWH can also affect the dynamics of the downstream FWHs based on the pathway of the drain cooling liquid. Dynamics of FWHs not only affect the amount of steam extracted but also the final feed water temperature entering the economizer thus plays a key role in the heat rate of the power plant. Therefore a detailed dynamic model of the FWHs is desired that can capture the complex interactions in the FWHs discussed above especially the dynamic change in the size of the zones in the FWHs and the amount of steam extracted and the hot and cold stream outlet temperatures. As such a model is currently not available in the existing literature, it was desired to develop that as part of this work.

Recently a comprehensive review of dynamic modeling of thermal power plants was provided (Alobaid et al., 2016). A dynamic model of an SCPC power plant developed in the process simulation software Apros was used to investigate operational flexibility and transient behavior (Starkloff et al., 2015). Under sliding-pressure operation, the load was decreased from $100 \%$ to $27.5 \%$ in six steps in 185 minutes, i.e. at a ramp rate of 0.4\%/min (Starkloff et al., 2015). Energy utilization in a $660 \mathrm{MW}$ SCPC power plant under load-following condition has been studied using a model developed in the GSE software (Wang et al., 2017). The GSE model was used to study energy-saving opportunities during load-following by considering a typical coal consumption rate. A 50\% load change under sliding-pressure mode was obtained with a maximum ramp rate of $0.5 \% /$ minute. The ramp rates considered in both these studies are far below the cycling demands and current industrial practices of about 3-8\% change per minute. In addition, none of these studies included the industry-standard coordinated control system (CCS). Recently, another dynamic model of an SCPC power plant was developed in Apros and validated against steady-state and transient plant data (Hentschel et al., 2017). However, few details about the control configuration, except that of load control and main steam temperature control were provided. Also, no disturbance rejection studies were conducted. In another work, advanced control strategies were developed and implemented for power plant cycling. Control performance of three model predictive control strategies was compared (He \& Lima, 2018). Therefore, it was desired to develop improved control strategies and evaluate both their servo control and disturbance rejection performances for load ramp rates in the desired range of 3-8\% load change per minute.

In summary, this works seeks to fill in the following gaps in the existing literature: 
1) Due to the typical arrangement of the various boiler components and the steam extractions from the steam turbine that are used in the FWHs, the SCPC plant is a highly mass and heat integrated system. There is a need of high fidelity plant-wide dynamic model of the SCPC plant capturing the interactions of the key equipment items in this highly integrated system.

2) Existence of the industry standard CCS is not considered while developing the control strategies in the limited literature that exists in this area, thus severely limiting their reallife implementation. To this end, control of the main steam temperature is one of the critical tasks of the CCS. A lower temperature than desired leads to inefficiency of the system. A higher temperature than desired can lead to considerable damage to the boiler components and the turbine. However the main steam temperature is a time-delay system with high nonlinearity thus improved control strategies are likely to improve the control performance of this important loop.

3) There is a need of a high fidelity three zone model of the FWH that can capture the dynamic change in the size of desuperheating, condensing and possibly subcooling zone under loadfollowing operation including FWHs that receives drain cooling liquid along with the extraction steam. The model can be used for investigating variable area control strategy for FWH for minimizing heat rate under load-following operation.

4) Furthermore, existing studies have not investigated very fast (higher than $2 \%$ load change per minute) load changes that lead to control challenges.

Specific objectives of this research are to:

Objective \#1: Develop an integrated dynamic model for SCPC plant for NETL Baseline Case B12B.

Objective \#2: Develop a control system for an integrated dynamic model for SCPC plant.

Objective \#3: Develop improved controllers for maintaining main steam temperature and compare its performance with traditional configurations.

Objective \#4: Development of a 1-d three-zone FWH model.

Objective \#5: Investigation of tracking control and disturbance rejection performances. 


\section{Development of Dynamic Model:}

\section{Objective \#1: Develop an integrated dynamic model for SCPC plant for NETL Baseline Case}

B12B.

Before we talk about model development, let us look at the plant configuration. The SCPC power plant considered in this work consists of a once-through steam boiler with a single steam reheating stage. There are four main sections: the feedwater treatment and heating sections, the supercritical boiler section that includes air fans as well as the air preheater, the ST section, and the flue gas treatment section, including some consideration for acid gas recovery (AGR). The configuration of the plant is shown in Figure 1, as adapted from the NETL study (Fout et al., 2015). The referenced configuration also includes $\mathrm{CO}_{2}$ capture, but a detailed model of that section is not included as a part of the current work. Nevertheless, the steam extraction for the AGR section was modeled to correctly characterize the power produced in the ST; these extraction flows were assumed to change proportionally with load. Another important note is that the coal feed in Error! $\mathbf{R}$ eference source not found. is located after the coal pulverizers, which were not considered as part of this work. It should also be noted here that the double ended arrows indicate extracted steam flowing to be used as a heating medium and the then-cooled effluent returned to the surface

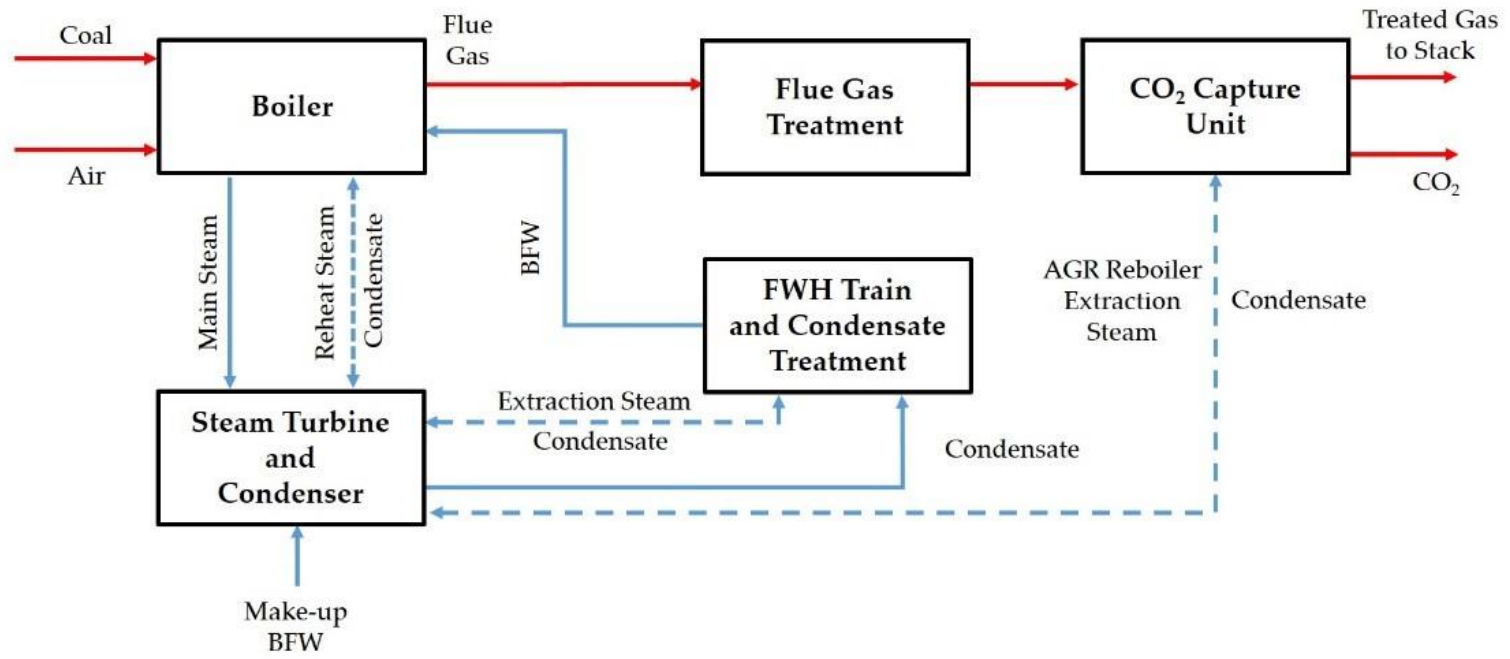

Figure 1. SCPC Power Plant Block Flow Diagram

condenser in the ST section.

In the boiler, pulverized coal is combusted using pre heated air producing hot flue gas. The boiler section consists of various components including an economizer, water wall, separator, 
reheater, multiple superheaters, two-stage attemperation for the main steam, and one-stage attemperation for the reheated steam. Under nominal condition, the supercritical steam at $593.3^{\circ} \mathrm{C}$ and 241.2 bar is sent to the HP turbine, where it is expanded to 47 bar in three stages. The expanded steam is then returned to the boiler where it is reheated to $593.3^{\circ} \mathrm{C}$, before it is sent to a three-stage IP turbine and subsequently to the five LP turbines. To enhance the overall power cycle efficiency, steam is extracted from the turbines for feedwater heating. Exhaust steam from LP turbine and extraction drains from low pressure FWH are condensed in the surface condenser and collected in the hotwell. The condensate is then pumped to the deaerator through two low pressure feedwater heaters and a drain cooler. In the deaerator, extraction steam from the IP turbine is used to remove dissolved oxygen. From the deaerator, boiler feedwater is pumped to three high pressure feedwater heaters and a drain cooler and is heated up to $290^{\circ} \mathrm{C}$ before sending it to the economizer.

The section describes development of a dynamic model of the SCPC plant in the APD software by first developing a valid pressure-flow network in the steady-state SCPC model in the AP software. This modeling task requires connecting the pressure nodes in the SCPC plant through flow nodes that relate pressure drop with volumetric flow rate (Turton et al., 2018). In dynamic simulations, specification of equipment sizes, their geometries, and orientations are crucial for capturing the transient behavior of the system. Volumetric holdup in equipment items affects the rate of accumulation, which is one of the key factors that affect the transient response. Each vessel is sized based on its steady-state operating conditions. Their design and configurational details are

then used in the APD model. As a part of development of integrated dynamic SCPC model, following sub models were developed as discussed below.

\subsection{Boiler Model:}

The water wall section of the boiler is modeled as a stoichiometric reactor where coal is combusted. The current model of the water wall section considers complete combustion of carbon, sulphur and hydrogen. During load-following especially during low load operation, incomplete combustion of carbon may occur. To maximize carbon burnout, excess air is usually increased at low load operation, which, in turn, leads to increased heat losses through the stack. This inefficiency at low loads operation is modeled using the results from the existing literature (Hanak et al., 2015). 
The boiler includes economizer, water wall, primary superheater, platen superheater, finishing superheater, and reheater. Typical inlet and outlet temperatures of the water and flue gas in these sections are estimated based on the NETL baseline study (Fout et al., 2015), information available in the open literature, and the energy balance calculations. Gas-side dynamics of SCPC boilers are very fast in comparison to the water/steam side. Therefore, in this work, gas-side dynamics have been neglected, and the gas side is assumed to be instantaneous. The water/steam side of the boiler is modeled with due consideration of thermal and volumetric holdup. Figure 2 represents schematic of the two sections in this boiler model.

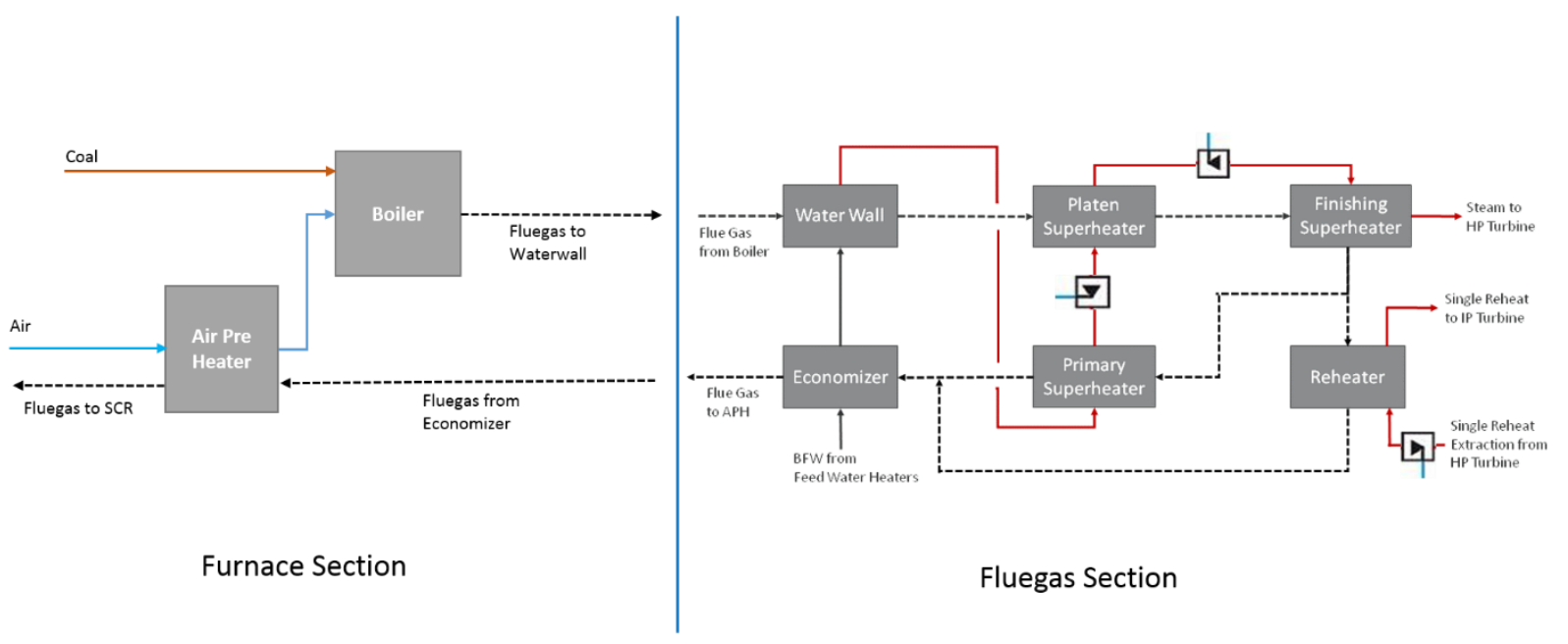

Figure 2. Schematic of Boiler Model

The flue gas exiting the boiler section is sent to the flue gas desulfurization (FGD) unit. Since this work primarily focuses on the dynamics of the front end of the power plant, models of back end sections like the flue gas treatment section are very simple. A simple stoichiometric reactor with $98 \%$ conversion of $\mathrm{SO}_{2}$ was developed for the FGD section where the $\mathrm{SO}_{2}$ in the flue gas reacts with lime slurry to form calcium sulfite that is then oxidized with air to form gypsum. The flue gas finally leaves the system via the carbon capture unit.

\subsection{Fan Model:}

The primary air (PA) and forced draft (FD) fans are used for providing air to the pulverizers and burners in the boiler, respectively. During load-following operation of the plant, changes in these air flow rates affect the energetics in the boiler and the auxiliary power requirements. Therefore, 
the control system needs to be designed appropriately. For large power plants, the PA and FD fans are typically operated by variable frequency drives (VFDs) that modulate the fan speed to obtain the desired flow rate. A family of curves available in the open literature for similar sized fans is scaled to match the desired range of head and flow. Then, a quadratic function between the head and flow is regressed to the family of curves simultaneously where each regression coefficient is considered to be a linear function of RPM.

\subsection{Feed Water Heater Model:}

In the initial version of the plant-wide dynamic model, Aspen Exchanger Design and Rating (EDR) is used to size each of the FWHs as a shell-and-tube heat exchanger based on its steadystate operating conditions. Aspen EDR sizes heat exchangers based on a constrained optimization, accounting for the process conditions within an economic framework. Sizing information for the FWHs including the volumes and metal masses of the shells and tube bundles, is used in the APD models. Feedwater heaters play and important role in SCPC plants especially during load following and part load operations under sliding pressure operation. Hence, a detailed first principle model of FWH is also developed in Aspen Custom Modeler (ACM) which will be described in Chapter 5.

Figure 3 shows the layout of the feedwater pretreatment and heating section of the plant with one deaerator and seven total exchangers consisting of five FWHs and two drain coolers (DCs) (Fout et al., 2015). The main difference between the FWHs and the DCs is that in the FWHs, heating is accomplished primarily using the latent heat from the extracted steam whereas in DCs, the sensible heat of the condensate from the FWHs is used for heating the feedwater. Extracted steam from HP Stages 1 and 2 are fed to FWH 1 and FWH 2, with an extraction from IP Stage 1 fed to FWH 3.

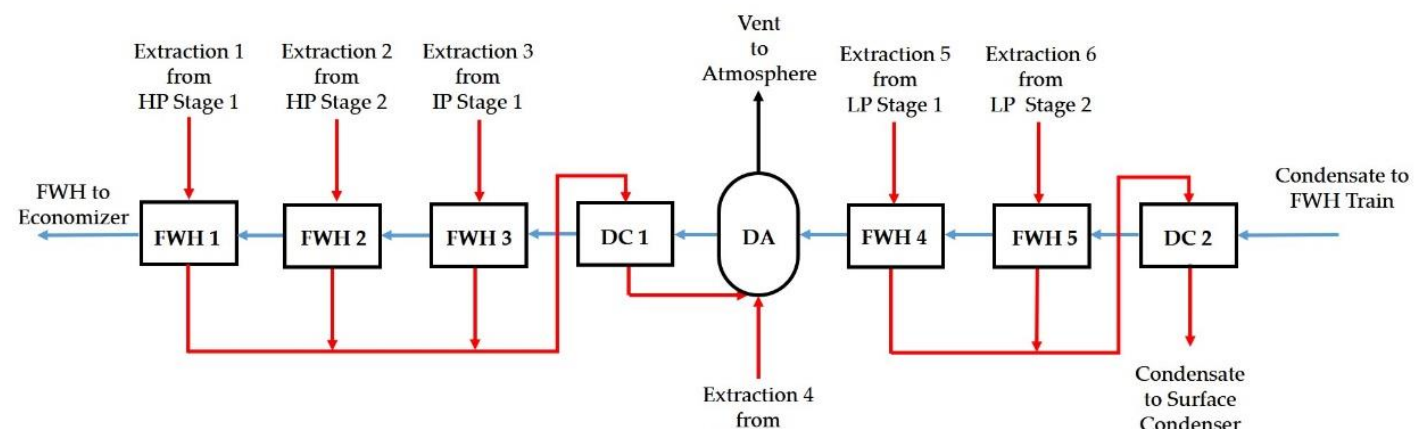

Figure 3. Feedwater Pretreatment and Heating Section Block Flow Diagram 
The condensate from these three FWHs is sent to DC 1 and subsequently to the deaerator. In the deaerator, extracted steam from IP Stage 2 is used for removing dissolved oxygen. Extracted steam from LP Stage 1, and LP Stage 2 is fed to FWH and FWH 5, respectively. The condensate from these two FWHs is sent to DC 2 and subsequently to the surface condenser.

\subsection{Turbine Model:}

Three separate ST models are considered to capture the operating characteristics of the various stages of the ST. As a part of SCPC dynamic model development, following models were developed (Sarda et al., 2018) by modifying the ST model developed by Liese (Liese, 2014).

\section{Leading (Governing) Stage}

2. High-Pressure (HP), Intermediate-Pressure (IP), and Low-Pressure (LP) Stages

3. Final Stage before Condenser

Figure 2 shows the layout of the turbine section of the SCPC plant. The HP steam from the finishing superheater of the boiler feeds the governing stage. There are three stages in the HP section. Extraction from the 1st stage of the HP turbine section is sent to FWH 1, with extractions 2 and 3 to FWHs 2 and 3 from the 2nd HP stage and 1st IP stage. After the HP section, steam is heated to $593^{\circ} \mathrm{C}$ under the nominal condition by sending it through two reheaters with inter-stage attemperation. The reheated IP steam is sent to the IP section of the turbine that comprises of two stages. There is one extraction from the IP section connected to FWH 4, from the first IP stage. After the IP turbines there are auxiliary extractions connected to various reboilers and a single turbine for auxiliary equipment, and the steam goes to the LP section that comprises of five stages, with two extractions to FWHs 5 and 6, after stages 1 and 2, respectively. The effluent steam from the final LP stage is then fed to a surface condenser where it is condensed with cooling water $(\mathrm{CW})$. The condenser is integrated with a hotwell from where the FWH pump returns water to the feedwater treatment and heating section. 


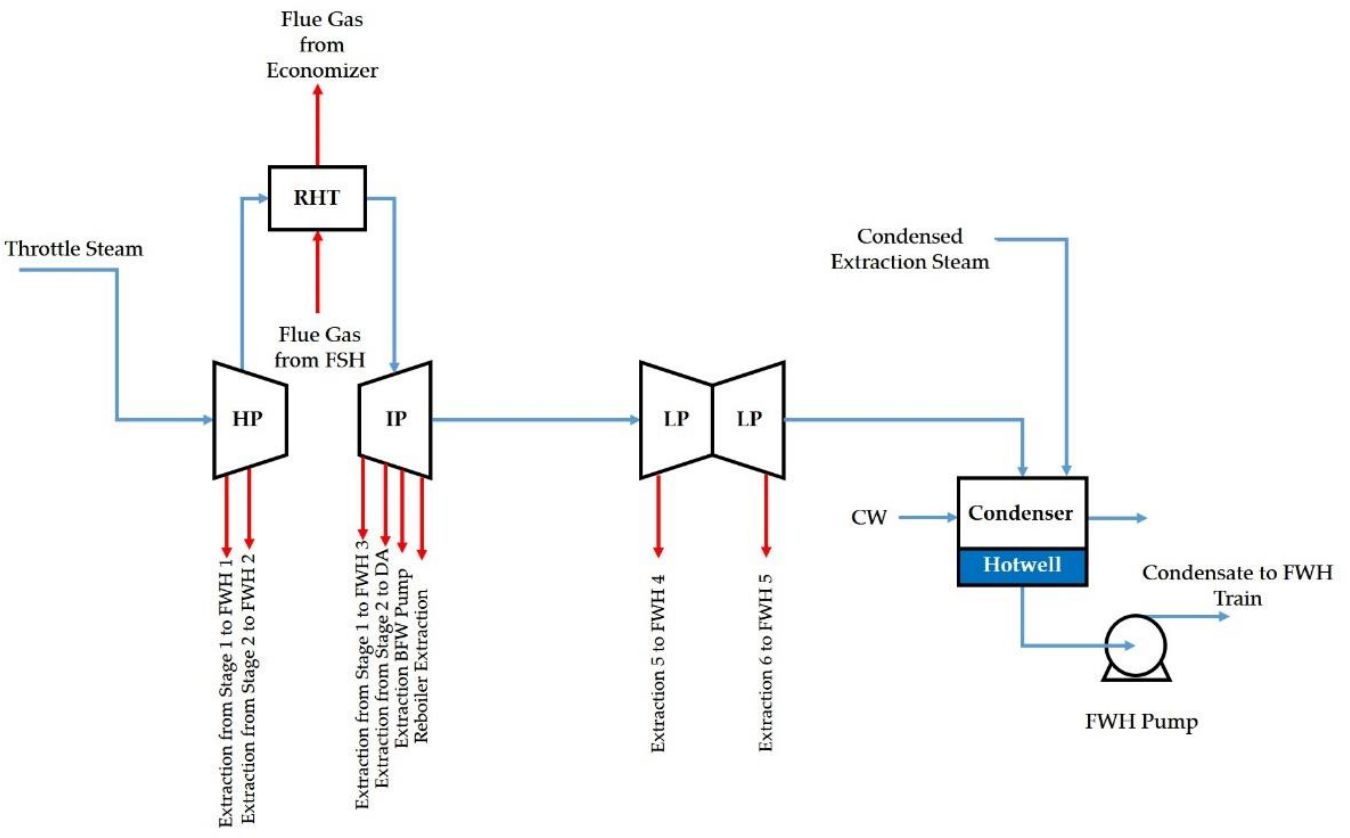

Figure 2. Turbine Section Block Flow Diagram

\subsection{Integration:}

All the sub models mentioned above were imported and integrated in APD to develop and integrated dynamic model for SCPC plant. Specific component lists with appropriate physical property packages are assigned to the individual sections in APD to accurately model the properties without considering the zero-flow components in specific streams and equipment models, thereby improving convergence properties and reducing computational time.

Table 1 compares the results of the simulation at full-load condition for the SCPC plant-wide dynamic model developed in this study and the steady-state NETL baseline study (Fout et al.,2015). 
Table 1. Steady State Validation

\begin{tabular}{ccccc}
\hline Parameter & Unit & $\begin{array}{c}\text { NETL Baseline } \\
\text { Study }\end{array}$ & SCPC Model & Error \\
\hline Coal Flow Rate & tonne/h & 225 & 228 & $1.53 \%$ \\
Gross Power & $\mathrm{MW}$ & 641 & 620 & $-3.28 \%$ \\
Net Power & $\mathrm{MW}$ & 550 & 532 & $-3.21 \%$ \\
Heat Rate & $\mathrm{kJ} / \mathrm{kWh}$ & 11086 & 11629 & $4.90 \%$ \\
Main Steam Pressure & $\mathrm{MPa}$ & 24.2 & 24.1 & $-0.37 \%$ \\
Main Steam Temperature & ${ }^{\circ} \mathrm{C}$ & 593 & 593 & $0.00 \%$ \\
Main Steam Flow Rate & tonne/h & 2003 & 2027 & $1.19 \%$ \\
\hline
\end{tabular}

Table 1 shows good agreement between SCPC model results and NETL baseline study. However, we can see that difference in coal flow rate, main steam flow rate and net power produced which effectively has $4.9 \%$ difference in heat rate. The turbines in SCPC model calculates efficiency whereas NETL baseline study uses constant turbine efficiency which results in higher power production. Similarly, NETL baseline study considers main steam temperature to be $593{ }^{\circ} \mathrm{C}$ without any attemperation whereas SCPC model considers attemperation system which impacts the main steam flow rate but is required to be modelled given the importance of main steam temperature. 


\section{Development of Control System:}

\section{Objective \#2: Develop a control system for an integrated dynamic model for SCPC plant.}

As mentioned earlier, the water-side of the SCPC system is a time-delay system that makes the design of the control system challenging. In addition, steam properties and heat transfer characteristics are highly nonlinear as the system transitions from the supercritical to subcritical region or vice versa during load-following. Furthermore, the highly complex configuration of the FWHs, coupled with the sliding-pressure operation that changes the pressure of the steam extractions leads to considerable further challenges in the control system design. The CCS is implemented as the supervisory layer that exploits the regulatory control as degrees of freedom to achieve the control objectives during load following.

\section{$\underline{\text { Regulatory Control Layer: }}$}

Regulatory control loops maintain each control variable at its setpoint to minimize variability if and when conditions change. The regulatory control layer is developed using the minimum amount of control needed for dynamic convergence. It consists of 16 single-loop feedback controllers and 14 cascade control loops, where proportional-integral-derivative (PID) controllers are used. List of all these controllers is attached in Appendix. A few of these controllers are discussed in detail below. Under the nominal condition of the SCPC plant, phase separation does not take place in the separator that is located between the water wall and primary superheater. Therefore, under the nominal condition, the inventory on the water side is controlled in the hotwell and in the deaerator. The deaerator level is maintained by manipulating the incoming BFW flow rate while the hotwell level is maintained by manipulating the demineralized water flow rate to the hotwell, under the assumption that a condensate storage tank can be neglected.

\section{$\underline{\text { Supervisory Control Layer: }}$}

As noted before, the typical supervisory control layer for SCPC plants is the CCS, which helps to follow the load with due consideration of the synergies between the boiler and turbine and interactions among the manipulated and controlled variables. An overall CCS is developed in this work and implemented in APD as shown in Figure 5 (Sarda et al., 2018). The CCS calculates load- 
dependent set points for PA air flowrate, FD air flowrate and BFW flowrate based on correlations developed using integrated model. While the required coal flow rate for a desired power output can be calculated based on the calorific value of the coal and the overall system efficiency, the system efficiency changes under load-following operation. Therefore, the heat rate correction is considered while calculating the trim to the boiler master and the turbine master inputs.

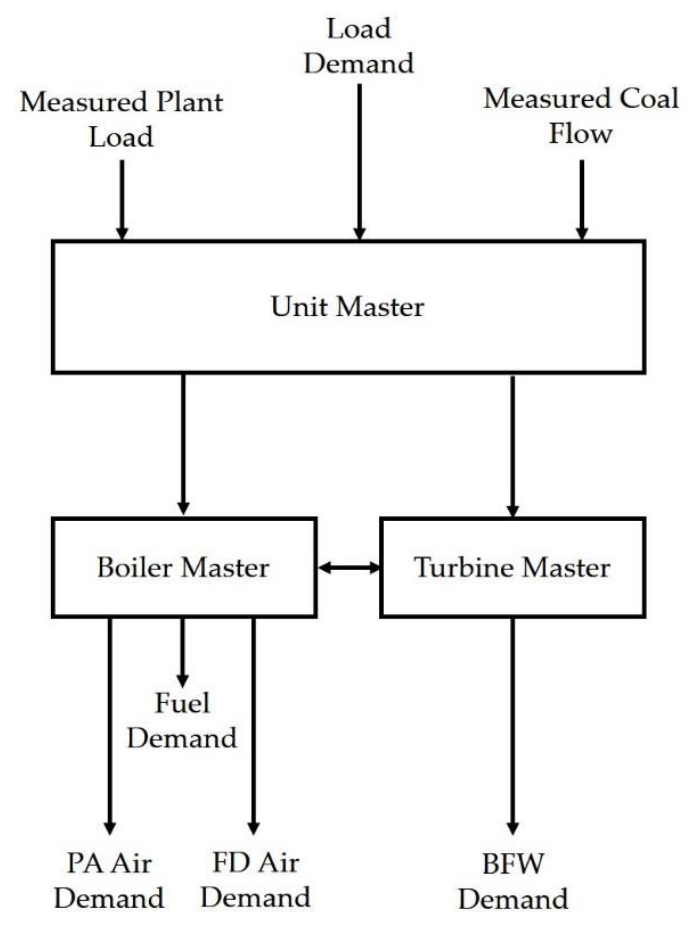

Figure 5. Coordinated Control System (CCS) Supervisory Layer

\subsection{Air Flow Rate Control:}

In the SCPC plant, the PA fan supplies air to the pulverizers transporting coal to the burners. Here, the air through the pulverizers is accounted for to accurately model the system interactions even though the pulverizers are not explicitly modeled. However, the main portion of the combustion air is provided by the FD fan. Based on the output signal of the boiler master controller, set points for air flow for the PA and FD fans are calculated. The corresponding set points for fan speeds in RPM are sent to the respective fan VFDs that modulate the frequencies to obtain the desired RPMs, based on the performance curve. The VFD control is represented by a simple PID controller. For the FD fan, a trim is provided based on the oxygen concentration in the boiler outlet flue gas. Proper control of the excess oxygen is crucial in that, if the excess oxygen drops too low, incomplete combustion might result leading to a process safety risk; if it becomes 
higher than needed, the higher heat loss through the exiting flue gas from the system would reduce the boiler efficiency.

Error! Reference source not found. and Error! Reference source not found. (Sarda et al ., 2018) show the control diagrams for the two fans that supply air to the boiler: the forced draft (FD) fan and the primary air (PA) fan, respectively.

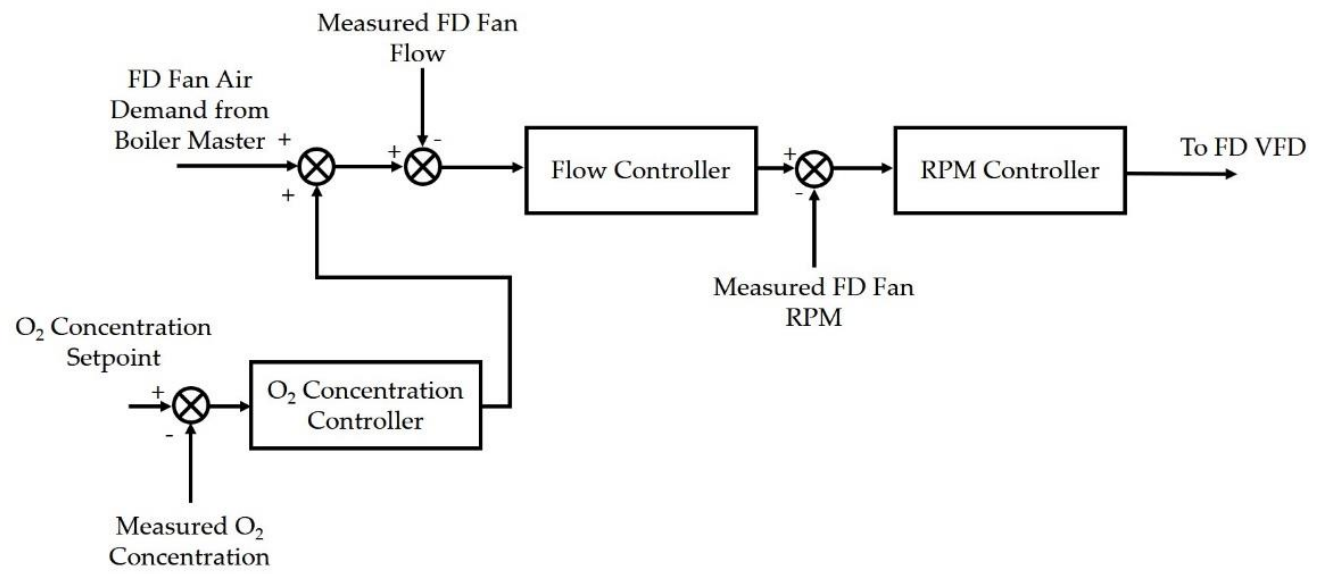

Figure 6. FD Fan Air Control Scheme

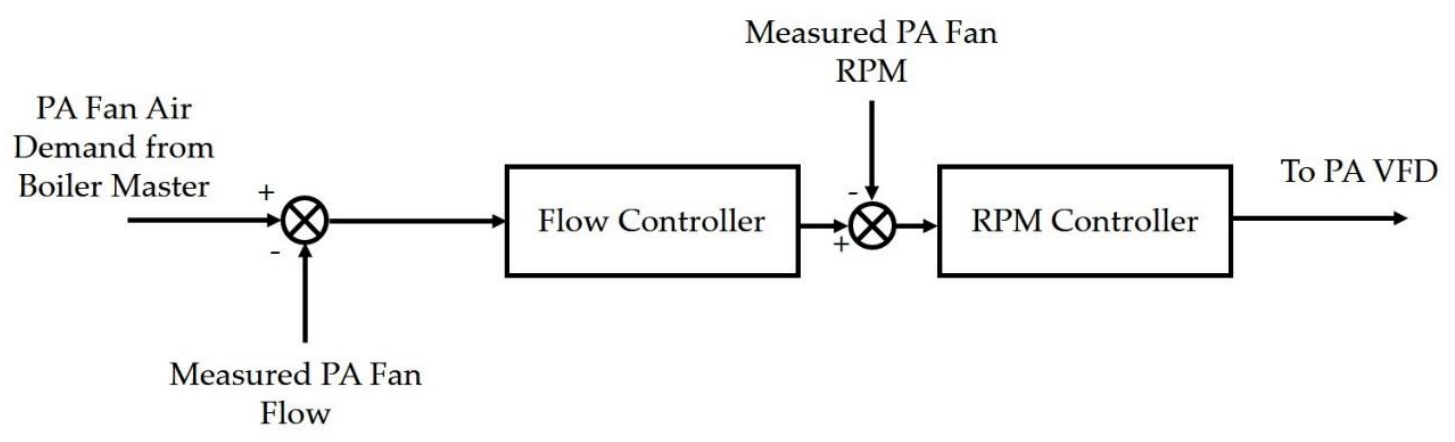

Figure 7. PA Fan Air Control Scheme 


\subsection{Boiler Feedwater Flowrate Control:}

Figure 8 (Sarda et al., 2018) represents the control diagram for the BFW flow control. The BFW flow plays a key role in achieving sliding-pressure operation and ensuring that the temperature constraints at various locations of the boiler can be satisfied. The BFW flow rate set point is load-dependent and corrected via the enthalpy at the water wall (WW) outlet in the boiler (Dong et al., 2011) and by the degree of attemperation as shown in Figure 8. A trim is also provided based on the water wall outlet enthalpy, that can be calculated based on the water wall outlet temperature and pressure. The CCS determines the load-dependent set point for the BFW controller based on the turbine master output signal. The trim, which is based on the opening of the main steam Attemperator 1 valve, ensures that the Attemperator 1 valve opening remains in the range that it has sufficient gain available to move this system in response to sudden load changes.

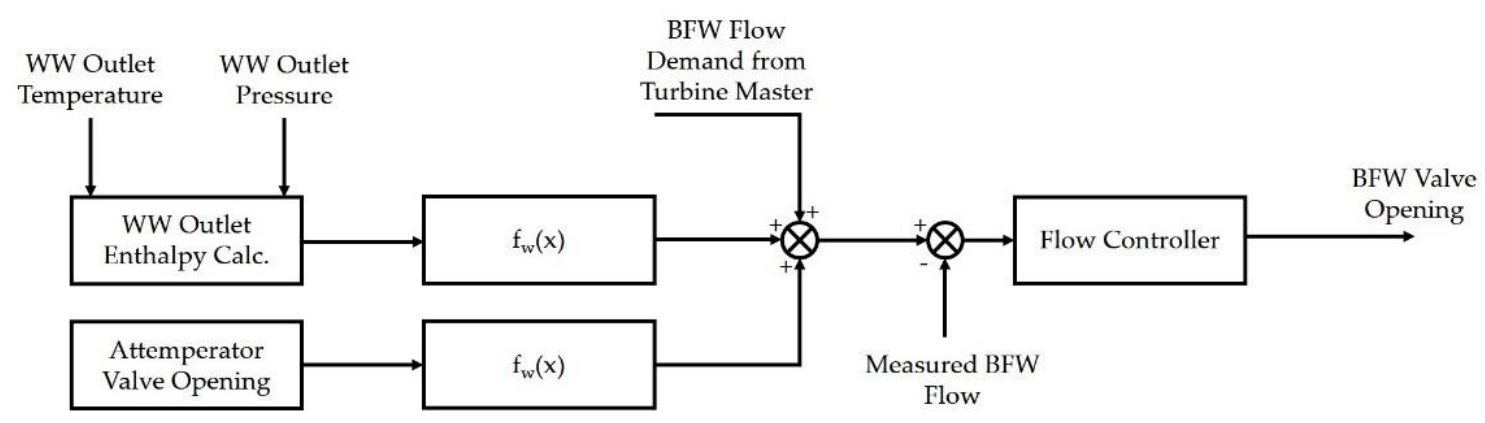

Figure 3. Boiler Feedwater Flow Control Scheme

Objective \#3: Develop improved controllers for maintaining main steam temperature and compare its performance with traditional configurations.

\subsection{Main Steam Temperature Control:}

Tight control of the main steam temperature is desired for maintaining efficiency during load following. A lower temperature than desired leads to inefficiency of the system. A higher temperature than desired can lead to considerable damage to the boiler components and the turbine. Temperature of the main steam is controlled by attemperation using BFW spray at two locations: the first immediately before the platen superheater $(\mathrm{SH})$ and the second immediately before the finishing SH as shown in Figure 9 (Sarda et al., 2018). Here, the second attemperator plays the key 
role in controlling the main steam temperature by regulating the spray flow, while the first attemperator assists by ensuring that the second attemperator spray is within a set range of operation, leaving room for changes in response to disturbances or fast load changes.

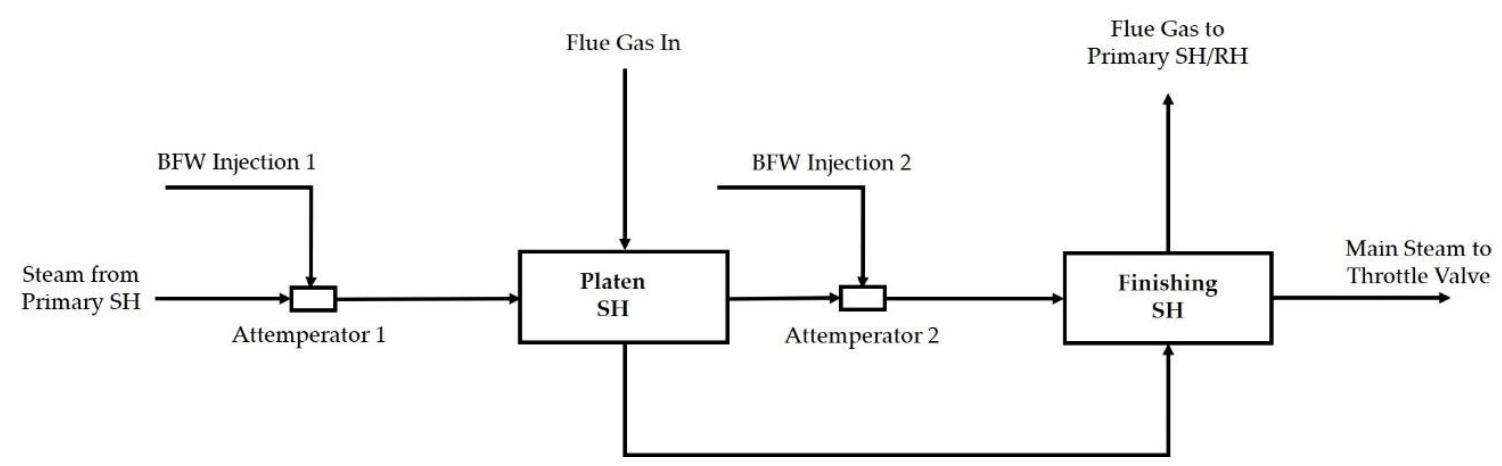

Figure 9. Schematic of High-Pressure Steam Attemperation

Three configurations for main steam temperature control are investigated here, where the manipulated variable is the BFW flow rate injected into Attemperator 2. Configuration 1 and Configuration 2 are typical control strategies reported in literature. Configuration 3 is the strategy proposed in this work.

\section{Configuration 1:}

Configuration 1, consists of a simple feedback loop where main steam temperature is controlled variable and BFW flow to Attemperator 2 is manipulated variable (Starkloff et al. 2017). As discussed before, large excursions in the main steam temperature should be avoided. However, there are considerable nonlinearities in the steam properties especially during transitions between the supercritical and subcritical regions. To improve the controller performance, as part of this work, a gain scheduling of main steam temperature controller is done and feedforward correction based on boiler feedwater flowrate at BFW pump discharge is done. A gain-scheduled controller is used in Configuration 1 to help improve control for this nonlinear system. The feedforward term helps to improve the disturbance rejection characteristics of the loop. Control scheme for main steam temperature control using Configuration 1 is shown in Figure 10 (Sarda et al., 2018). 


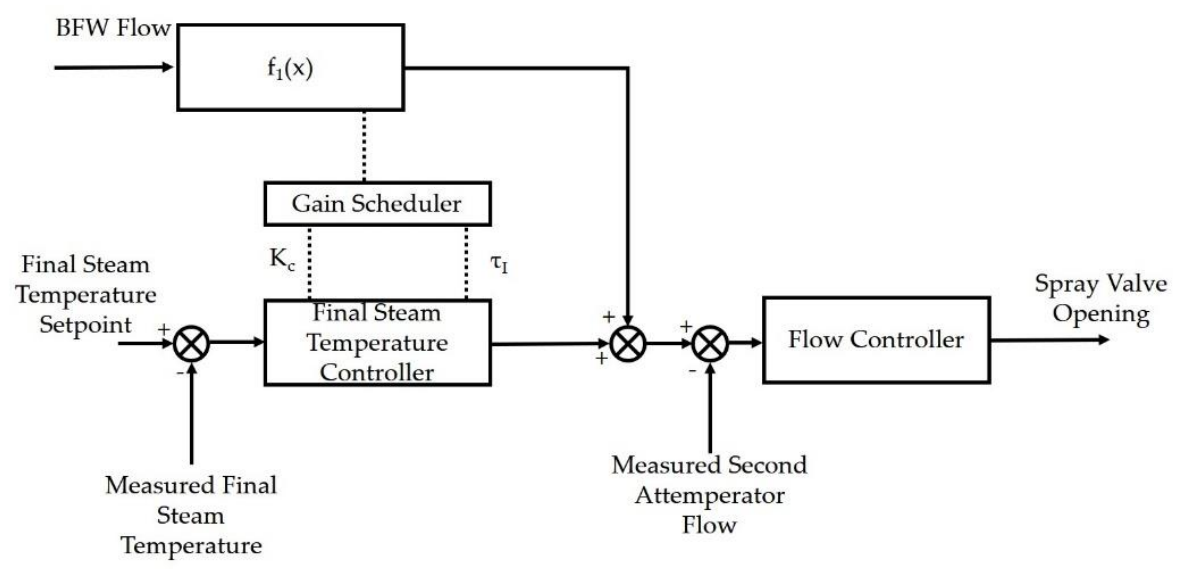

Figure 10. Configuration 1 Control Scheme for Final Steam Temperature

\section{Configuration 2:}

In Configuration 1, temperature of the main steam is controlled without any consideration of the intermediate steam temperature immediately after Attemperator 2. The temperature of this intermediate steam responds faster to changes in the BFW spray flow rate in comparison to the main steam temperature, which lags due to the thermal and volumetric holdup of the finishing SH. In Configuration 2, the intermediate steam temperature controller manipulates the BFW injection flow rate to Attemperator 2 (Draganescu et al., 2015). The PID controller that is used for the main steam temperature control generates the set point for the intermediate steam temperature controller. It should be noted that this configuration does not consider any feedforward correction. Control scheme for main steam temperature control using configuration 2 is shown in Figure 11(Sarda et al., 2018).

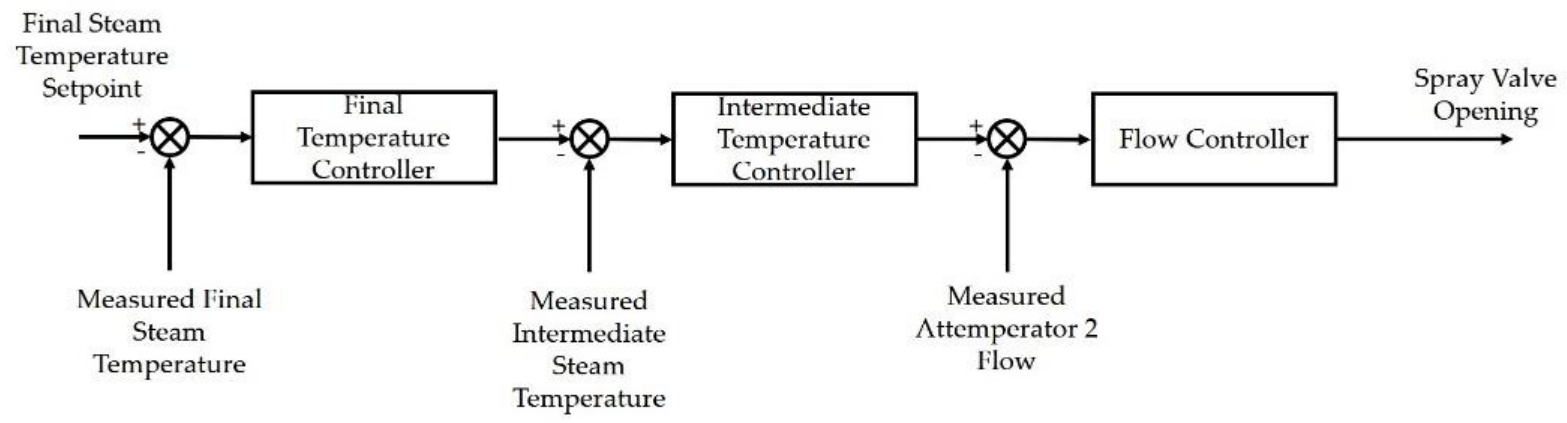

Figure 11. Configuration 2 Control Scheme for Final Steam Temperature 


\section{Configuration 3:}

As noted before, there is significant time-delay in the water/steam side of the SCPC plant. For closed-loop stability of such systems, a smaller gain has to be used in the PID controller leading to sluggish response that is undesired for main steam temperature control. One classic approach for control of a time-delay system is the Smith Predictor (Ogunnaike \& Ray, 1994). For designing the Smith Predictor, the finishing SH is represented as a first-order process with time-delay as follows:

$$
y(s)=\frac{K_{c} e^{-\theta s}}{\tau_{s}+1} * u(s)
$$

A minor feedback loop is introduced in the conventional feedback structure, along with a feedforward compensation. The block diagram for the Configuration 3 control scheme developed in this work as shown in Figure 12 (Sarda et al., 2018).

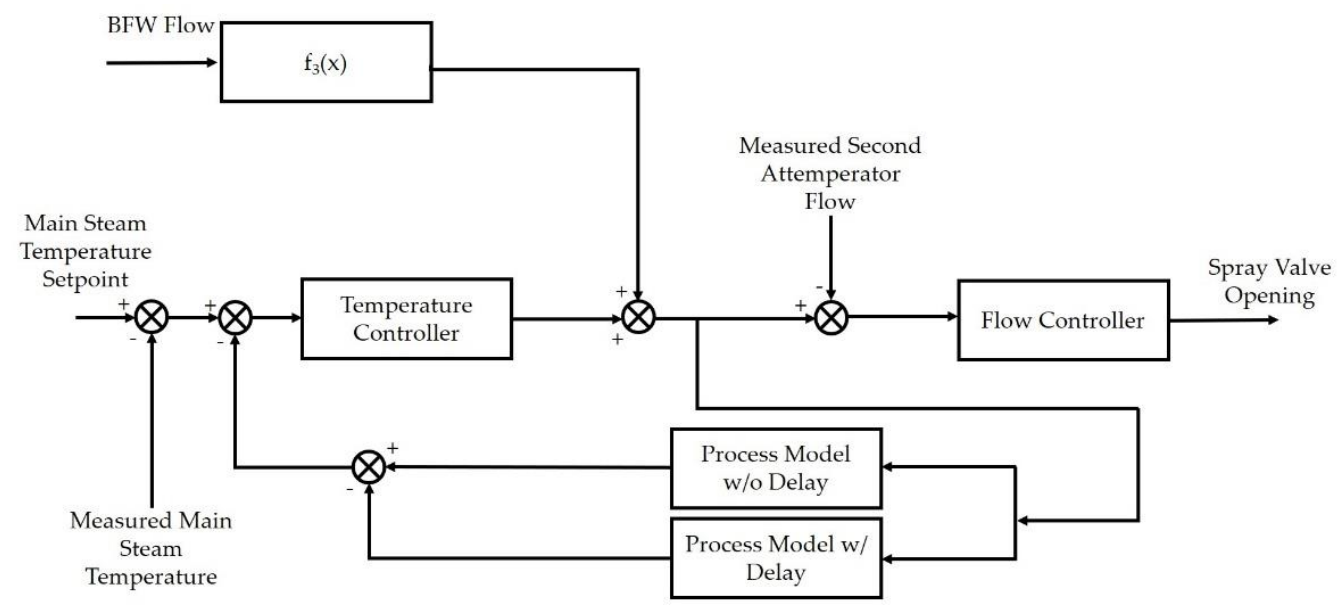

Figure 12. Configuration 3 (Smith Predictor) Control Scheme for Main Steam Temperature 


\subsection{Reheat Steam Temperature Control:}

In continuation to main steam temperature, reheat steam temperature also has huge impact on plant efficiency during load following operation. Deviations in main steam temperature are directly propagated and reflected in reheat steam temperature. Large deviations in the reheat steam temperature can lead to undesired creep and fatigue in the reheater tubes, intermediate pressure turbine and low pressure turbine components. Also, lower reheat steam temperature can cause significant condensation at low stage turbines. While we have considered three configurations for main steam temperature control, reheat steam temperature is controlled using a dual control strategy. As a part of dual control strategy, we have primary control of reheat steam temperature using damper at the vertical downpass of boiler, which controls the fluegas flowrate through reheater / primary superheater and secondary control of reheat steam temperature using BFW attemperation spary to reheat steam. Secondary control using BFW attemperation is only helpful when reheat steam temperature is in excess to its set point. Figure 13 shows the schematic of dual control strategy used for reheat steam temperature

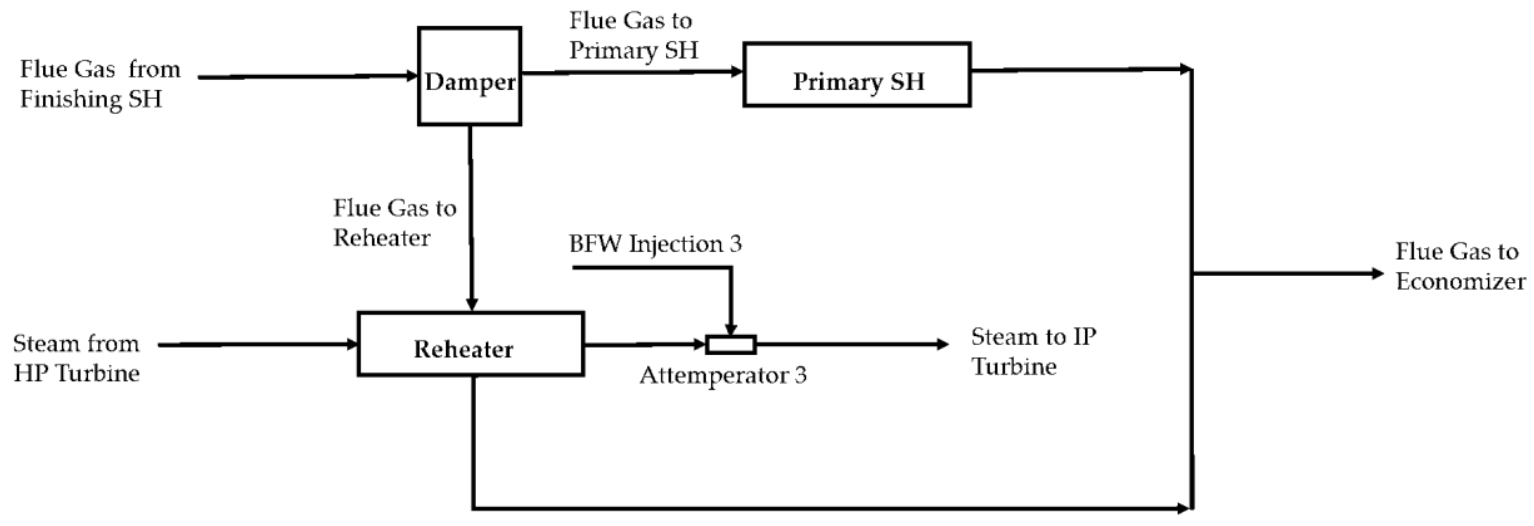

Figure 13. Schematic of Reheat Steam Temperature Control

In primary control for maintaining reheat steam temperature, damper positioning is manipulated variable and reheat steam temperature upstream to Attemperator 3 is controlled variable. Based on the reheat steam temperature measurement, flue gas exiting from finishing superheater is diverted to either reheater or primary superheater using a damper. Control scheme developed for primary control is shown in Figure 14. 
Reheat Steam

Temperature

Setpoint

(Upstream

Attemperator 3)

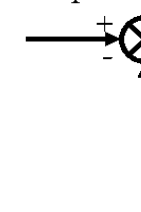

$$
\begin{gathered}
\text { Measured Reheat } \\
\text { Steam } \\
\text { Temperature } \\
\text { (Upstream } \\
\text { Attemperator 3) }
\end{gathered}
$$

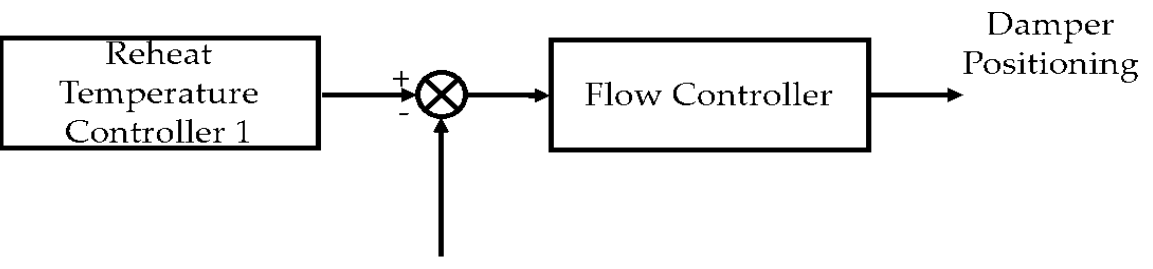

Measured Fluegas

Flowrate to

Reheater

Figure 14. Control Scheme for Primary Control for maintaining Reheat Steam Temperature

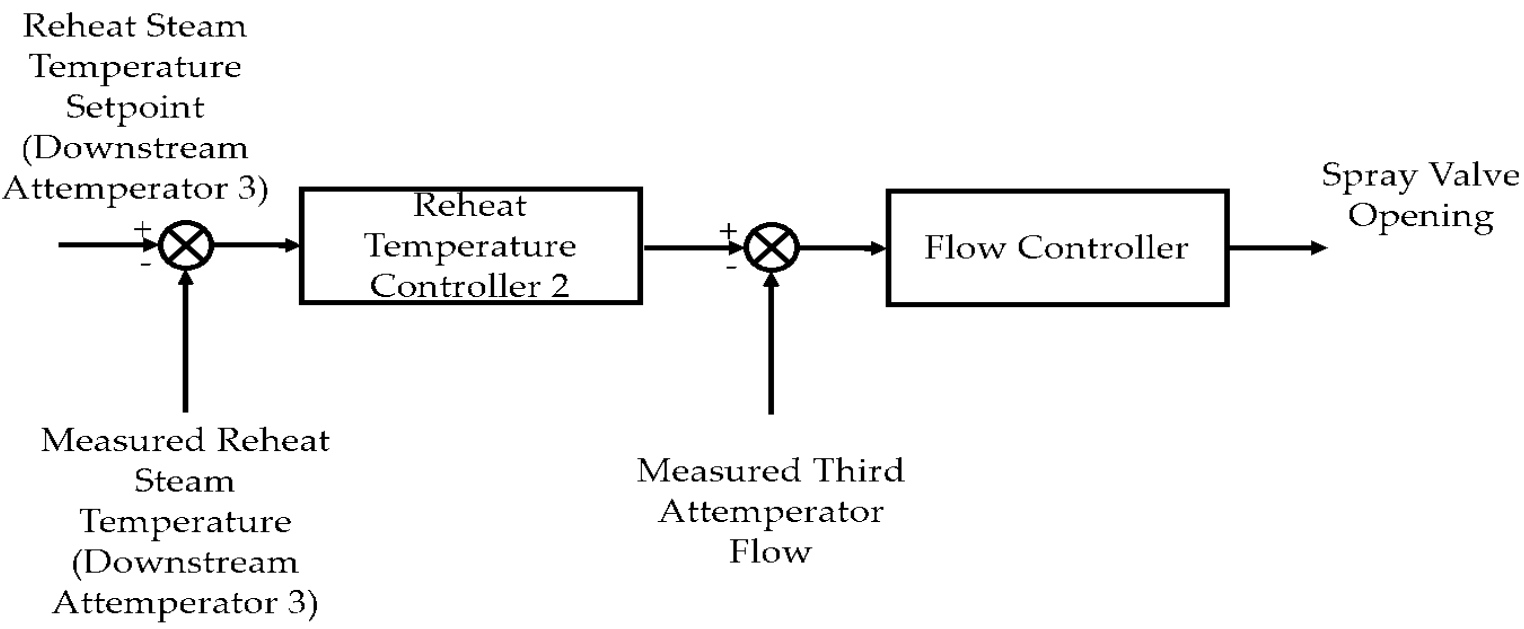

Figure 15. Control Scheme for Secondary Control for maintaining Reheat Steam Temperature

In secondary control for maintaining reheat steam temperature, BFW flow injected into Attemperator 3 is manipulated variable and reheat steam temperature downstream to Attemperator 3 is controlled variable. Control scheme developed for secondary control is shown in Figure 15. 


\section{Development and design validation of FWH model:}

\section{Objective \#4: Development of a 1-d three-zone FWH model.}

In Chapter 2.3, a simple model of the FWH was discussed. Those FWHs were modelled using HeatX blocks in Aspen Library and supported with design information obtained using Aspen EDR. As a part of this thesis, we have also developed a detailed first-principle custom model for FWH. In this chapter, development of the detailed FWH model will be discussed in detail.

Figure 16 represents a schematic of a typical FWH. FWHs are part of regenerative heating in Rankine cycle to improve overall efficiency of the cycle. In FWH, as shown in Figure 16, boiler feedwater is heated inside tubes whereas extraction steam gets condensed in the shell side. Extraction steam is desuperheated, condensed and subcooled in shell side before it leaves the heat exchanger.

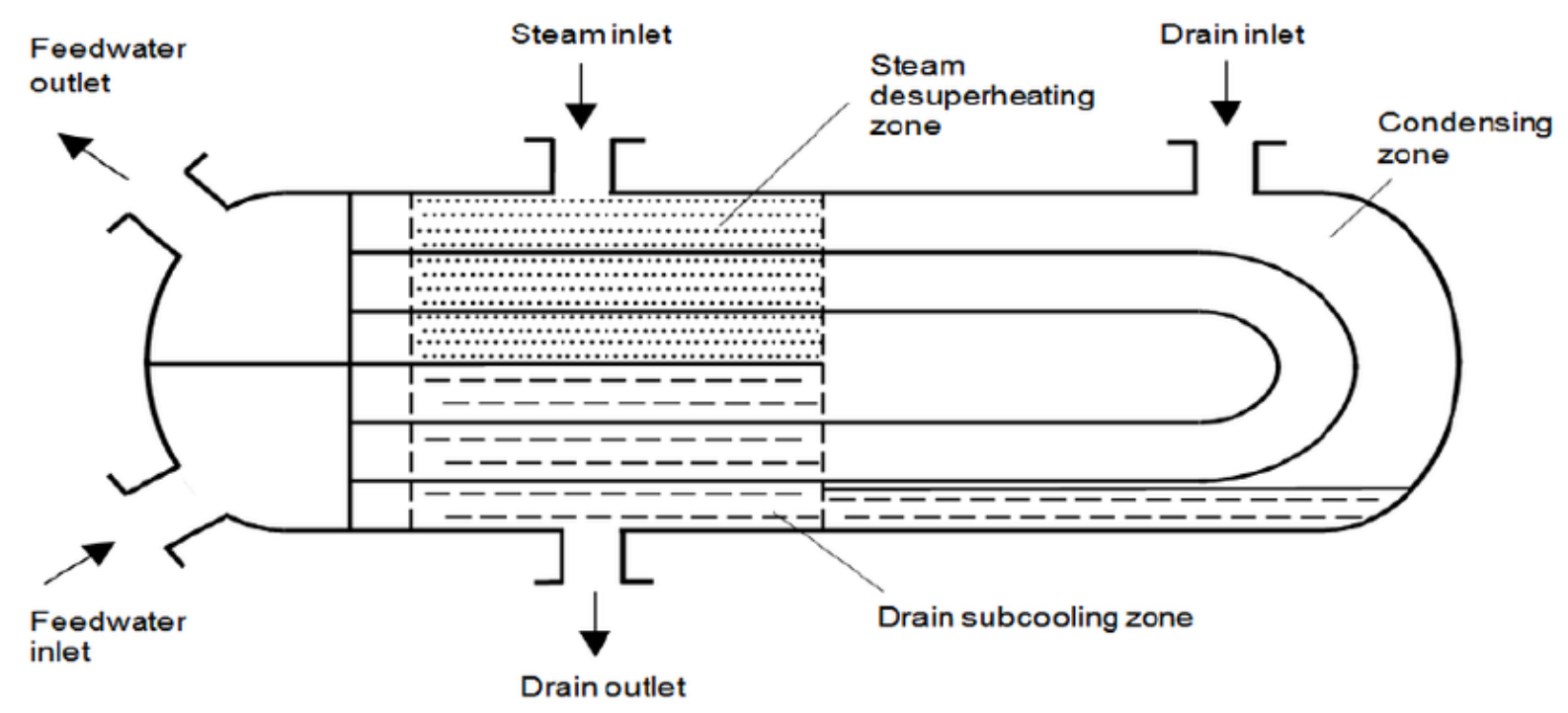

Figure 16. Schematic of Feed Water Heater (Madron, 2013)

Under steady state conditions, the mass flowrate of the extraction steam matches with the amount of steam that condenses in the FWHs. Since any uncondensed steam cannot leave the FWHs, the imbalance between the extraction steam and the steam that condenses under transient condition leads to change in the operating pressure of the FWHs, which in turn affect the extraction flow rate since there is no valve on the extraction line. In addition, as the condensation temperature 
changes, the heat exchanger duty also changes. In operation of FWH, liquid level in shell side is user input and the change in the pressure also affects the relative size of the desuperheating and condensation zones at a given liquid level. The model developed will be able to take into account these complicated interactions. It will also take into account the change in the heat transfer coefficients based on the dynamic change in the size of the zones.

\subsection{Modelling Approach:}

For the modelling of feedwater heater, boiler feedwater flows inside tube which is cold side. This cold side is discretized in " $\mathrm{Nx}$ " nodes along the length of exchanger in " $\mathrm{x}$ " domain. Extraction steam is desuperheated, condensed and subcooled inside shell of heat exchanger. This hot side is discretized in "Ny" nodes along the height of exchanger in "y" domain. To capture thermal holdup and dynamics of tube, tubes are discretized in "Nr" nodes along the tube thickness in "r" domain. Figure 17 depicts the discretization in feed water heater.

For cold side and hot side, discretization is done using the backward finite difference method whereas tube calculations are performed using the central finite difference method.

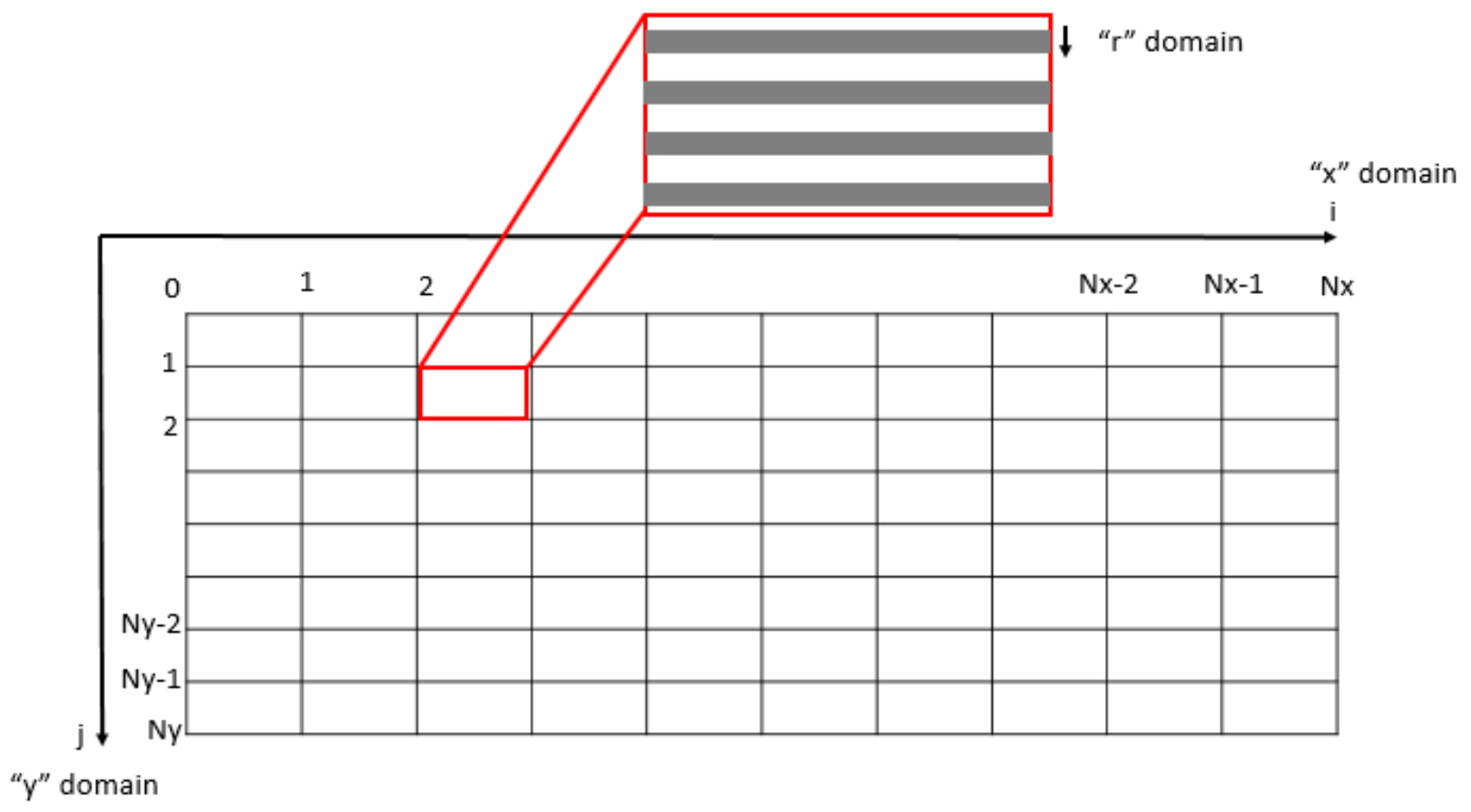

Figure 17. Discretization in Feed Water Heater 
Following assumptions have been made:

- $\quad$ Hot side pressure drop in de-superheating and condensation zone is negligible.

- Tubes are considered to be of U-Tube configuration.

- Hot side is considered to be mixed at each node whereas cold side is considered to be unmixed.

Following variable are provided as input variable.

- $\quad$ Cold side inlet flowrate

- $\quad$ Cold Side inlet temperature

- $\quad$ Cold Side inlet pressure

- $\quad$ Exchanger geometry

- $\quad$ Liquid level inside shell.

Following variable are calculated as output variable.

- $\quad$ Hot Side flowrate

- Hot side pressure

- Relative size of condensation and desuperheating section

- $\quad$ Cold Side outlet temperature

- $\quad$ Cold Side outlet pressure

- $\quad$ Hot side outlet temperature

- Hot and cold side heat transfer coefficient at each node

- $\quad$ Tube temperature at each node.

As shown in Figure 18, following heat transfer mechanisms take place in the FWHs:

- Convective heat transfers from the steam/condensate bulk to the tube outer surface

- Conductive heat transfers through tube wall

- Convective heat transfers from tube inner wall to the BFW inside tube 


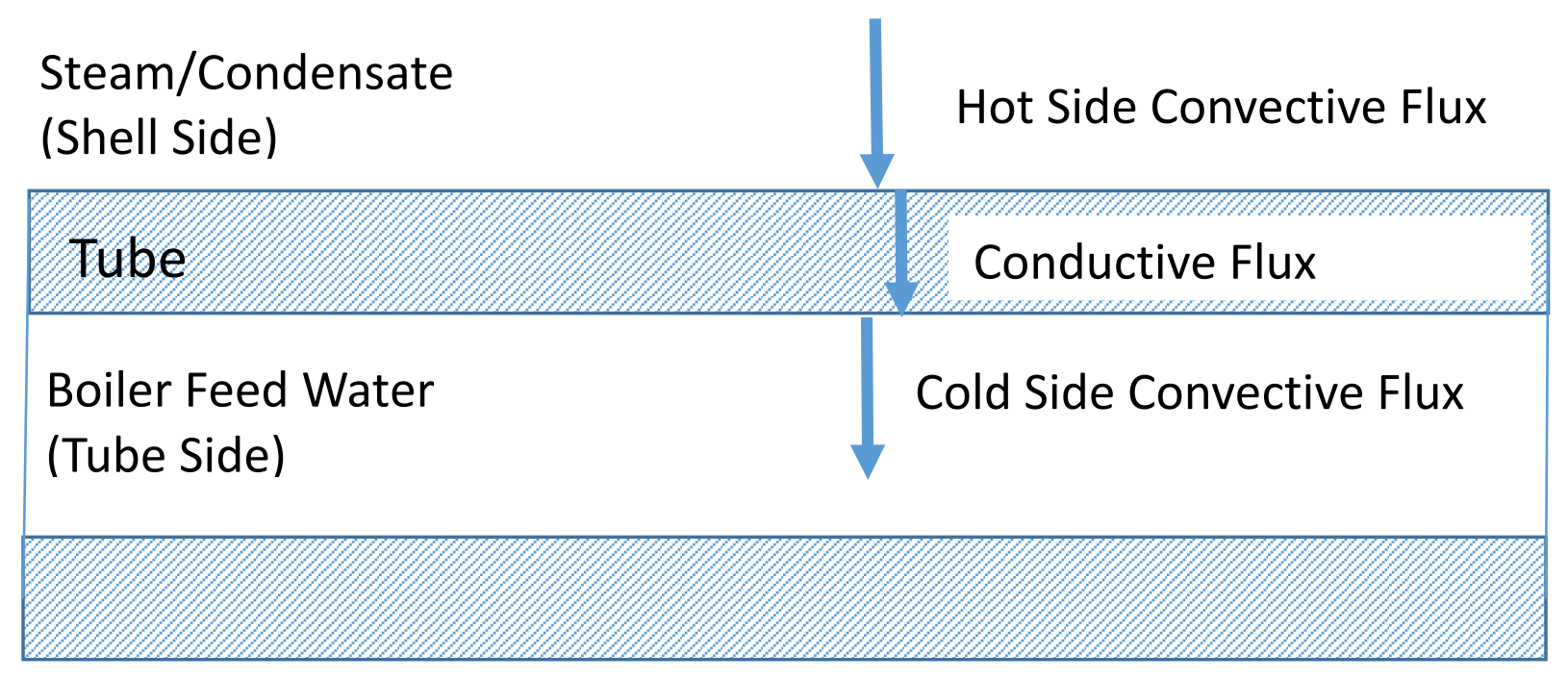

Figure 18. Heat Transfer Mechanisms in the FWHs

\subsubsection{Cold Side Mass and Energy Balance:}

As mentioned earlier, feedwater flows through $U$ tube and figure 19 represents the path of boiler feedwater in feedwater heater. The feedwater enters at the lower half and comes out from upper half of feed water heater.

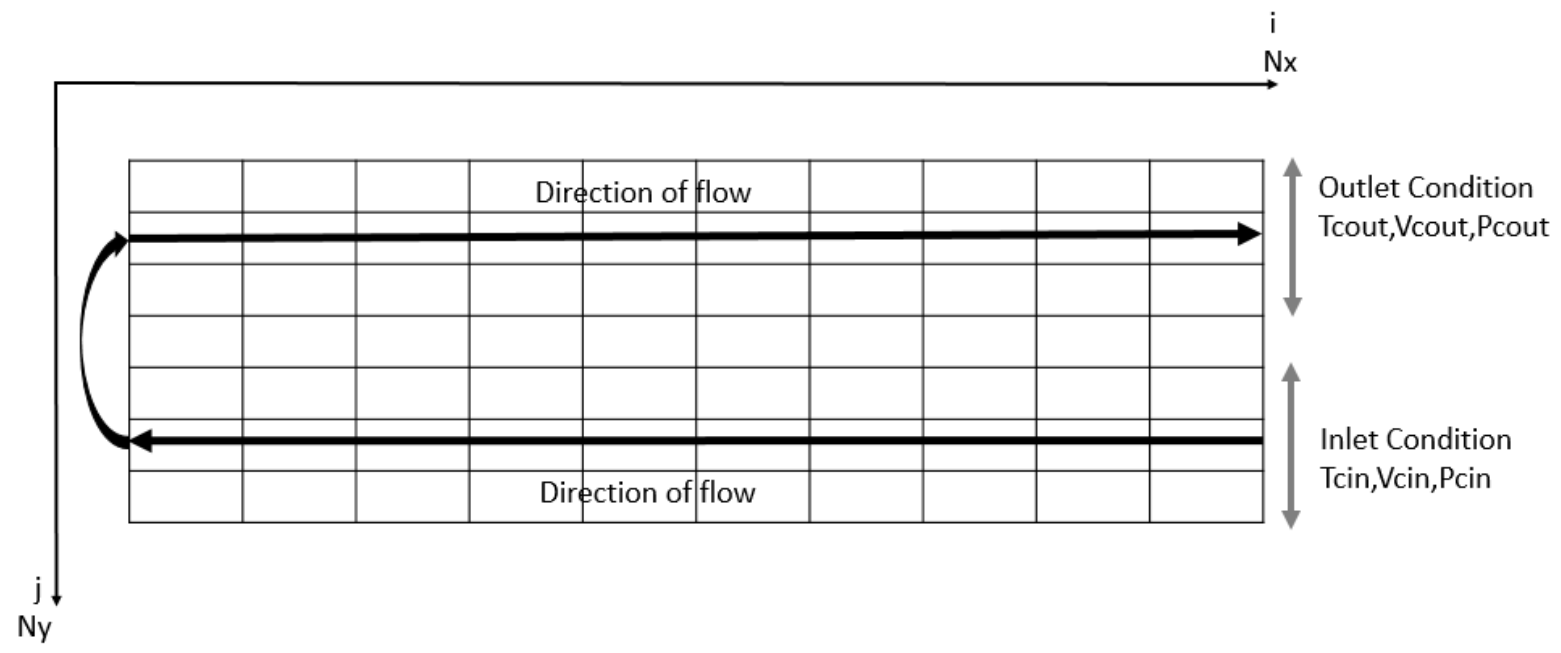

Figure 19. Cold Side Flow Pattern

As shown in figure 18 , based on inlet conditions, cold side velocity $v_{c}$, cold side temperature $T_{c}$ and cold side pressure $P_{c}$ is calculated at inlet nodes. Based on temperature, inlet 
enthalpy $h_{c}$ and inlet density $\rho_{c}$ is also calculated using properties call in ACM. Following are the mass and energy conservation equations for the cold side:

$$
\begin{gathered}
\frac{\partial \rho_{c}}{\partial t}+\frac{\partial\left(\rho_{c} v_{c}\right)}{\partial x}=0 \\
\frac{\partial\left(\rho_{c} h_{c}\right)}{\partial t}+\frac{\partial\left(\rho_{c} h_{c} v_{c}\right)}{\partial x}=\frac{\partial P c}{\partial t}+q_{w a l, c}
\end{gathered}
$$

The outlet conditions from the lower half is considered as the inlet boundary condition for the upper half as shown in Figure 19 to represent U-tube configuration. Then, mass and energy balance equations are solved again in direction of flow in upper half of shell and thus cold side

enthalpy $h_{c}$, cold side density $\rho_{c}$, cold side velocity $v_{c}$, cold side temperature $T_{c}$ and cold side pressure $P_{c}$ are calculated at each node.

\subsubsection{Tube Wall Energy Balance:}

Thermal holdup in the FWH tube wall can affect their temperature dynamic. Therefore, the following energy conservation equation is considered for the tube wall energy balance:

$$
\frac{\partial}{\partial t}\left(\rho_{t} C_{p, t} T_{\text {tube }}\right)=k_{\text {tube }}\left\{\left(\frac{1}{r} \frac{\partial}{\partial r}\left(r \frac{\partial T_{\text {tube }}}{\partial r}\right)\right\}\right.
$$

\subsubsection{Hot Side Mass and Energy Balance:}

As mentioned earlier, extraction steam along with extraction drain enters the shell. Extraction drain from upstream feedwater heater is flashed which results in generation of desuperheated steam and condensate. Desuperheated steam directly joins with the extraction steam while the condensate directly goes to the subcooling region. Extraction steam is de-superheated and condensed inside shell where liquid level is not maintained and this zone is called as "desuperheating and condensation zone". The condensate and extraction drain are subcooled inside shell where liquid level is maintained and this zone is called as "subcooling zone". The shell is divided into two sections based on user defined liquid level " $\phi$ " namely desuperheating and condensation zone and subcooling zone. 


\section{Desuperheating and condensation zone:}

For desuperheating and condensation zone, based on extraction steam inlet conditions, hot side vapor velocity $v_{h v}$, hot side temperature $T_{h}$ and hot side pressure $P_{h}$ is calculated at inlet nodes. Based on temperature, inlet vapor enthalpy $h_{h v}$ and inlet vapor density $\rho_{h v}$ is also calculated using properties call in ACM. The hot side mass and energy balance equations are solved in desuperheating and condensation zone. Based on hot side temperature $T_{h}$, desuperheating and condensation regime are differentiated from each other and appropriate equations are applied. Following are the equations are solved using backward finite difference method along the direction of flow.

$$
\begin{gathered}
\frac{\partial \rho_{h v}}{\partial t}+\frac{\partial\left(\rho_{h v} v_{h v}\right)}{\partial y}+m_{c o n d}=0 \\
\frac{\partial\left(\rho_{h v} h_{h v}\right)}{\partial t}+\frac{\partial\left(\rho_{h v} h_{h v} v_{h v}\right)}{\partial \mathrm{y}}+q_{w a l, \mathrm{~h}}+m_{\text {cond }} \text { hsat, liq }=\frac{\partial P_{h}}{\partial t}
\end{gathered}
$$

As the mass and energy balance equations are solved in desuperheating and condensation zone, hot side vapor enthalpy $h_{h v}$, hot side vapor density $\rho_{h v}$, hot side vapor velocity $v_{h v}$, hot side temperature $T_{h}$ and hot side pressure $P_{h}$ are calculated at each node.

\section{Subcooling zone:}

For subcooling zone, based on extraction drain inlet conditions and total condensate from desuperheating and condensation zone, hot side liquid velocity $v_{h l}$, hot side temperature $T_{h}$ and hot side pressure $P_{h}$ are calculated at inlet nodes. Based on temperature, inlet liquid enthalpy $h_{h l}$ and inlet liquid density $\rho_{h l}$ are also calculated using properties call in ACM. The hot side mass and energy balance equations are solved in subcooling zone. Following mass and energy balance equations are considered:

$$
\begin{gathered}
\frac{\partial \rho_{h l}}{\partial t}+\frac{\partial\left(\rho_{h l} v_{h l}\right)}{\partial y}=0 \\
\frac{\partial\left(\rho_{h l} h_{h l}\right)}{\partial t}+\frac{\partial\left(\rho_{h l} h_{h l} v_{h l}\right)}{\partial \mathrm{y}}+q_{w a l, \mathrm{~h}}=\frac{\partial P_{h}}{\partial t}
\end{gathered}
$$


As the mass and energy balance equations are solved in subcooling zone, hot side liquid enthalpy $h_{h l}$, hot side liquid density $\rho_{h l}$, hot side liquid velocity $v_{h l}$, hot side temperature $T_{h}$ and hot side pressure $P_{h}$ are calculated at each node.

\section{Overall mass balance:}

As mentioned earlier, the imbalance between the extraction steam and the steam that condenses under transient condition leads to change in the operating pressure of the FWHs, which in turn affect the extraction flow rate since there is no valve on the extraction line. The shell side pressure $P_{h}$ is calculated using following overall mass balance equation.

$$
\begin{gathered}
V_{\text {Shell }} \frac{d \rho_{h}}{d t}=\dot{m}_{h, v, \text { in }}-\dot{m}_{\text {cond,total }} \\
\dot{m}_{\text {cond,total }}=\int_{0}^{V_{\text {shell,eff }} \dot{m}_{\text {cond }} d V_{\text {shell,eff }}}
\end{gathered}
$$

where, $\dot{m}_{h, v, \text { in }}$ is extraction steam inlet flowrate and $\dot{m}_{\text {cond,total }}$ is total condensate in shell. 


\subsubsection{Heat Transfer Coefficient Calculations:}

Various heat transfer phenomena happen in the FWHs including heating boiler feed water inside tubes, de-superheating extraction steam around tube bundle, condensing extraction steam around tube bundle and subcooling extraction condensate around tube bundle. Heat transfer coefficients in FWHs can thus greatly vary in various locations of the FWHs.

\section{Heating boiler feed water inside tubes:}

For heating of boiler feedwater inside tubes, Gnielinski correlation is used. Equations/correlations are used to calculate cold side heat transfer coefficient are tabulated in Table 2.

Table 2. Heat Transfer Coefficient for water flowing inside tube (VDI heat Atlas, 2010)

\begin{tabular}{|c|c|}
\hline Equation & Description \\
\hline $\boldsymbol{R} \boldsymbol{e}_{c}=\frac{\rho_{c} v_{c} \boldsymbol{I D}}{\mu_{c}}$ & Reynolds Number \\
\hline $\operatorname{Pr}_{c}=\frac{C_{p, c} u_{c}}{k_{c}}$ & Prandtl Number \\
\hline$\xi_{c}=0.00128+0.1143 R e_{c}^{-0.311}$ & Frictional Coefficient \\
\hline$N u_{c}=\frac{\left(\frac{\xi_{c}}{8}\right) \operatorname{Re}_{c} \operatorname{Pr}_{c}}{1+12.7 \sqrt{\frac{\xi_{c}}{8}}\left(\operatorname{Pr}_{c}^{\frac{2}{3}}-1\right)}$ & Nusselt Number \\
\hline $\mathrm{h}_{\mathrm{c}}=\frac{N u_{c} \boldsymbol{k}_{c}}{I D}$ & Cold Side Heat Transfer Coefficient \\
\hline
\end{tabular}

\section{Heat transfer coefficient for steam desuperheating:}

For calculating the heat transfer coefficient in the desuperheating zone, following correlations are used considering in line tube arrangement for flow through a cross flow tube bundle as tabulated in Table 3 . 
Table 3. Heat Transfer Coefficient for desuperheating steam around tube bundle (VDI heat Atlas, 2010)

\begin{tabular}{|c|c|}
\hline Equation & Description \\
\hline$a=\frac{s_{1}}{O D}$ & Transverse Pitch Ratio \\
\hline$b=\frac{s_{2}}{O D}$ & Longitudinal Pitch Ratio \\
\hline$\psi=1-\frac{\pi}{4 a}$ & Void fraction \\
\hline$L_{c h a r}=\left(\frac{\pi}{2}\right) O D$ & Streamed Length of Tube \\
\hline$f_{A, \text { in -line }}=1+\frac{0.7\left(\frac{b}{a}-0.3\right)}{\psi^{1.5}\left(\frac{b}{a}+0.7\right)^{2}}$ & Factor for In Line Tube Arrangement \\
\hline$R e_{h v}=\frac{\rho_{h v} v_{h v} L_{c h a r}}{\mu_{h v} \psi}$ & Reynolds Number \\
\hline $\operatorname{Pr}_{h v}=\frac{C_{p, h v} u_{h v}}{k_{h v}}$ & Prandtl Number \\
\hline$N u_{t u r b, h v}=\frac{0.037 \operatorname{Re}_{h v}^{0.8} \operatorname{Pr}_{h v}}{1+2.443 \operatorname{Re}_{h v}^{-.01}\left(\operatorname{Pr}_{h v}^{2 / 3}-1\right)}$ & Turbulent Nusselt Number \\
\hline$N u_{l a m, h v}=0.664 R e_{h v}^{1 / 2} \operatorname{Pr}_{h v}^{1 / 3}$ & Laminar Nusselt Number \\
\hline $\mathrm{Nu}_{\text {tube,hv }}=0.3+\sqrt{N u_{l a m, h v}^{2}+N u_{t u r b, h v}^{2}}$ & Tube Nusselt Number \\
\hline$N u_{\text {bundle,hv }}=f_{A, \text { in-line }} N u_{\text {tube }, h v}$ & Tube Bundle Nusselt Number \\
\hline $\mathbf{h}_{\mathrm{h}}=\frac{N \boldsymbol{u}_{\text {bundle, }, v} \boldsymbol{k}_{h v}}{L_{c h a r}}$ & $\begin{array}{l}\text { Hot Side heat Transfer Coefficient } \\
\text { (desuperheating) }\end{array}$ \\
\hline
\end{tabular}


Heat transfer coefficient for steam condensation:

For calculating the hot side heat transfer coefficient for steam condensation, following equations/correlations are used as shown in Table 4.

Table 4. Heat Transfer Coefficient for condensation around tube bundle (Sarri et al., 2014)

\begin{tabular}{|c|c|}
\hline Equation & Description \\
\hline $\mathbf{R e}_{\mathrm{hl}}=\frac{\boldsymbol{\rho}_{\mathrm{hl}} * \mathbf{O D} * \mathbf{V}_{\mathrm{hl}}}{\mu_{\mathrm{hl}}}$ & $\begin{array}{l}\text { Reynolds Number } \\
\text { (Condensation) }\end{array}$ \\
\hline $\mathbf{h}_{\mathrm{gr}}=\frac{0.728 \mathbf{k}_{\mathrm{hl}}}{\mathbf{O D}}\left\{\frac{\rho_{\mathrm{hl}}\left(\boldsymbol{\rho}_{\mathrm{hl}}-\boldsymbol{\rho}_{\mathrm{hv}}\right) * \mathbf{g} * \lambda * \mathbf{O D}^{3}}{\mu_{\mathrm{hl}} \mathbf{k}_{\mathrm{hl}} \Delta \mathrm{T}}\right\}^{0.25}$ & $\begin{array}{l}\text { Gravity Dominated } \\
\text { HT Coefficient } \\
\text { (Condensation) }\end{array}$ \\
\hline $\mathbf{h}_{\mathrm{sh}}=\frac{0.59 \mathbf{k}_{\mathrm{hl}}}{0 \mathrm{D}} * \sqrt{\mathbf{R e}_{\mathrm{hl}}}$ & $\begin{array}{l}\text { Shear Dominated HT } \\
\text { Coefficient } \\
\text { (Condensation) }\end{array}$ \\
\hline$h_{h o}=\sqrt{0.5 h_{s h}^{2}+\sqrt{0.25 h_{s h}^{4}+h_{g r}^{4}}}$ & $\begin{array}{l}\text { Nominal HT } \\
\text { Coefficient } \\
\text { (Condensation) }\end{array}$ \\
\hline$h_{h j}=h_{h o j}\left[j^{5 / 6}-(j-1)^{5 / 6}\right]$ & $\begin{array}{l}\text { Hot Side HT } \\
\text { Coefficient } \\
\text { (Condensation) }\end{array}$ \\
\hline
\end{tabular}

\section{Heat transfer coefficient for subcooling:}

For calculating the heat transfer coefficient in the subcooling zone, following correlations are used considering in line tube arrangement for cross flow over a tube bundle as tabulated in Table 5 . 
Table 5. Heat Transfer Coefficient for subcooling liquid around tube bundle (VDI heat Atlas, 2010)

\section{Equation}

$$
\begin{array}{cc}
\boldsymbol{R e}_{\boldsymbol{h l}}=\frac{\boldsymbol{\rho}_{\boldsymbol{h l}} \boldsymbol{v}_{\boldsymbol{h l}} \boldsymbol{L}_{\boldsymbol{c h a r}}}{\boldsymbol{\mu}_{\boldsymbol{h l}} \boldsymbol{\psi}} & \text { Reynolds Number } \\
\boldsymbol{P r}_{\boldsymbol{h l}}=\frac{\boldsymbol{C}_{\boldsymbol{p}, \boldsymbol{h l}} \boldsymbol{u}_{\boldsymbol{h l}}}{\boldsymbol{k}_{\boldsymbol{h l}}} & \text { Prandtl Number }
\end{array}
$$

\section{Description}

$$
N u_{t u r b, h l}=\frac{0.037 \boldsymbol{R e}_{h l}^{0.8} \boldsymbol{P r}_{h l}}{1+2.443 \operatorname{Re}_{h l}^{-.01}\left(\operatorname{Pr}_{h l}^{2 / 3}-1\right)} \quad \text { Turbulent Nusselt Number }
$$

$$
N u_{l a m, h l}=0.664 \operatorname{Re}_{h l}^{1 / 2} \operatorname{Pr}_{h l}^{1 / 3} \quad \text { Laminar Nusselt Number }
$$

$$
\mathrm{Nu}_{\text {tube,hl }}=0.3+\sqrt{N u_{l a m, h l}^{2}+N u_{\text {turb,hl }}^{2}} \quad \text { Tube Nusselt Number }
$$

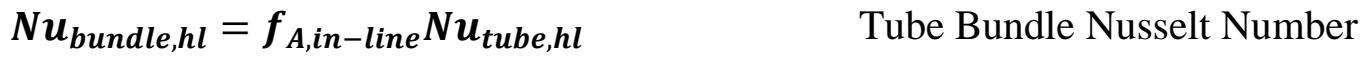

$$
\begin{aligned}
& \mathbf{h}_{\mathbf{h}}=\frac{\boldsymbol{N} \boldsymbol{u}_{\text {bundle,hl }} \boldsymbol{k}_{\boldsymbol{h l}}}{\boldsymbol{L}_{\text {char }}} \quad \begin{array}{c}
\text { Hot Side heat Transfer Coefficient } \\
\text { (Subcooling) }
\end{array}
\end{aligned}
$$

\subsubsection{Boundary conditions:}

Boundary conditions along with the relevant equations are shown in Table 6:

Table 6. Boundary condition

\section{Equation}

\section{Description}




\begin{tabular}{rr}
\hline$-\mathbf{q}_{\mathbf{h}}=\left.\mathbf{k}_{\mathbf{t}} \frac{\partial \mathbf{T}_{\mathbf{t}}}{\partial \mathbf{r}}\right|_{\mathbf{r}=\mathbf{D}_{\mathbf{0}, \mathbf{t}}}$ & Conduction from Tube outer wall to shell side \\
\hline $\mathbf{q}_{\mathbf{h}}=-\mathbf{h}_{\mathbf{h}} *\left(\mathbf{T}_{\mathbf{h}}-\mathbf{T}_{\mathbf{t o}}\right)$ & Convection heat flux per unit area in Shell \\
\hline $\mathbf{q}_{\mathbf{w a l}, \mathbf{c}}=\mathbf{q}_{\mathbf{c}} * \frac{\mathbf{4}}{\mathbf{D}_{\mathbf{i}, \mathbf{t}}}$ & $\begin{array}{c}\text { Convection heat flux per unit volume inside } \\
\text { tube }\end{array}$ \\
\hline $\mathbf{q}_{\mathbf{w a l}, \mathbf{h}}=\mathbf{q}_{\mathbf{h}} * \frac{\boldsymbol{\pi} \mathbf{O D ~ \mathbf { L } _ { \mathbf { t } } \mathbf { N } _ { \mathbf { t } }}}{\mathbf{L}_{\mathbf{t}} \mathbf{H}_{\mathbf{s}} \mathbf{W}_{\mathbf{s}}-\frac{\mathbf{\pi}}{\mathbf{4}} \mathbf{O D}^{\mathbf{2}} \mathbf{N}_{\mathbf{t}}}$ & Convection heat flux per unit volume in Shell
\end{tabular}

The dynamic FWH model is developed in ACM where for both water and steam properties IAPWS 95 was used. The resulting PDAES are solved using the method of lines.

Variable used in the chapter are denoted in Section 8.

\subsection{Design Validation:}

The model was validated with the design data of the FWHs from our Industrial Partner Plant (IPP). The maximum error between FWH model results and IPP design data is $3.83 \%$. The comparison is considered to be satisfactory.

\subsection{Load Following and sensitivity study:}

The developed FWH model is used for load-following studies. The plant load was decreased from $100 \%$ to $40 \%$ and operating conditions for one high pressure FWH and one low pressure FWH are obtained from the plant-wide model developed for NETL Baseline case B12B (Sarda et al., 2018). The hot-side inlet operating conditions for the specific high pressure and low pressure FWH are provided in Table 7.

Table 7. Operating conditions of the high pressure and low pressure FWH during load following

\begin{tabular}{|c|c|c|c|c|}
\cline { 2 - 5 } \multicolumn{1}{c|}{} & \multicolumn{2}{c|}{ High Pressure FWH } & \multicolumn{2}{c|}{ Low Pressure FWH } \\
\cline { 2 - 5 } \multicolumn{1}{c|}{} & Temperature & Pressure & Temperature & Pressure \\
\hline Load (\%) & ${ }^{0} \mathrm{C}$ & bar & ${ }^{0} \mathbf{C}$ & bar \\
\hline 100.00 & 391.11 & 83.63 & 241.56 & 5.14 \\
\hline
\end{tabular}




\begin{tabular}{|l|l|l|l|l|}
80.00 & 394.84 & 65.12 & 245.97 & 3.83 \\
\hline 60.00 & 396.56 & 45.15 & 255.27 & 2.82 \\
\hline 40.00 & 401.51 & 29.07 & 261.20 & 2.48 \\
\hline
\end{tabular}

Alongside hot side temperature and pressure, BFW inlet temperature and BFW flowrate are also subjected to change during load following.

Figure 20 represents effect of load following on the heat duty of FWH.

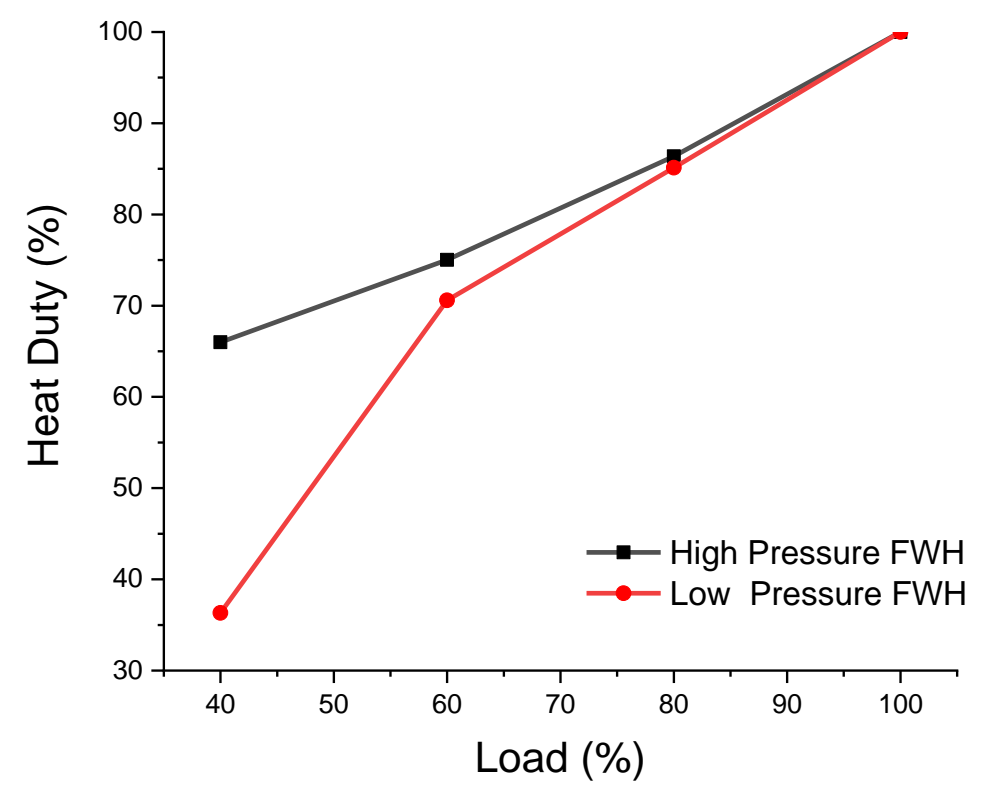

Figure 20. Effect of Load Following on FWH Duty

As shown in Figure 20, heat duty decreases as the load decreases for both high pressure and low pressure FWHs. For the low pressure FWH operating below $60 \%$ load, there is considerable decrease in the heat duty because of lack of availability of extraction steam at low loads for low pressure FWH. The KPI of FWH namely terminal temperature difference (TTD), drain cooling approach (DCA) and temperature rise (TR) also show expected trend during load following except for the low pressure FWH operating below $60 \%$ load.

Sensitivity studies are conducted to capture the effect of extraction steam inlet temperature and extraction steam pressure. Extraction steam inlet temperature is step increased by $60{ }^{0} \mathrm{C}$ and its effects on extraction steam flowrate, cold side outlet temperature and heat duty are studied. 
Figures 21 and 22 show that the step change results in $3.2 \%$ decrease in the extraction stem flowrate, $4.47^{0} \mathrm{C}$ rise in the cold side outlet temperature and $5.2 \%$ increase in the heat duty.

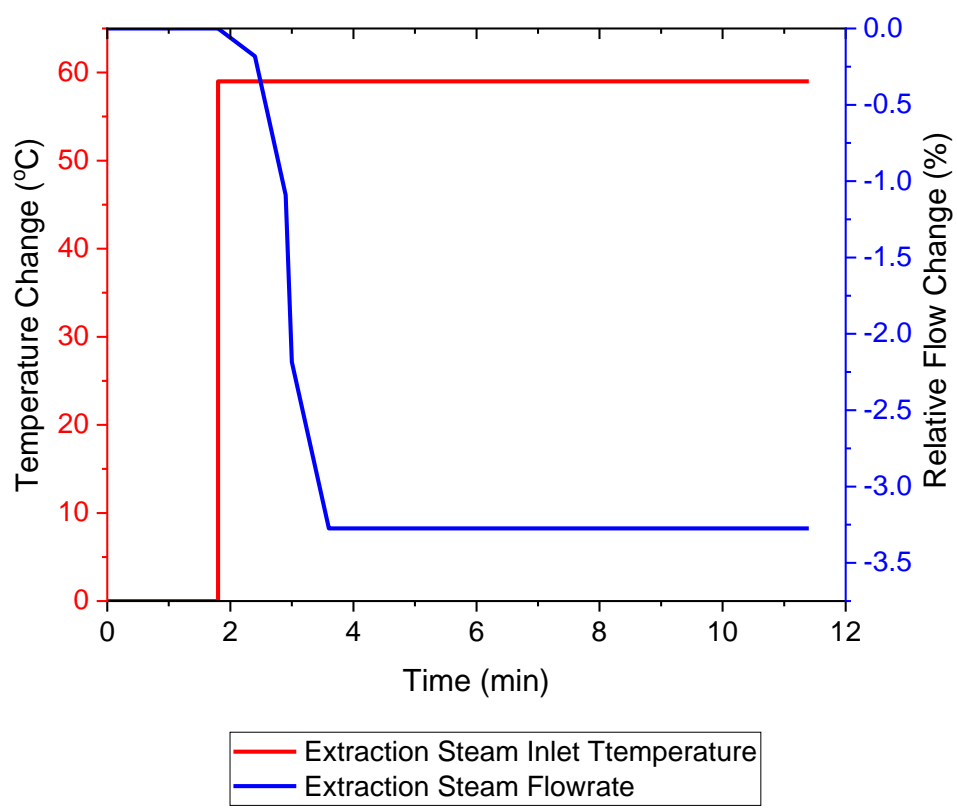

Figure 21. Effect of extraction steam temperature on extraction steam flowrate
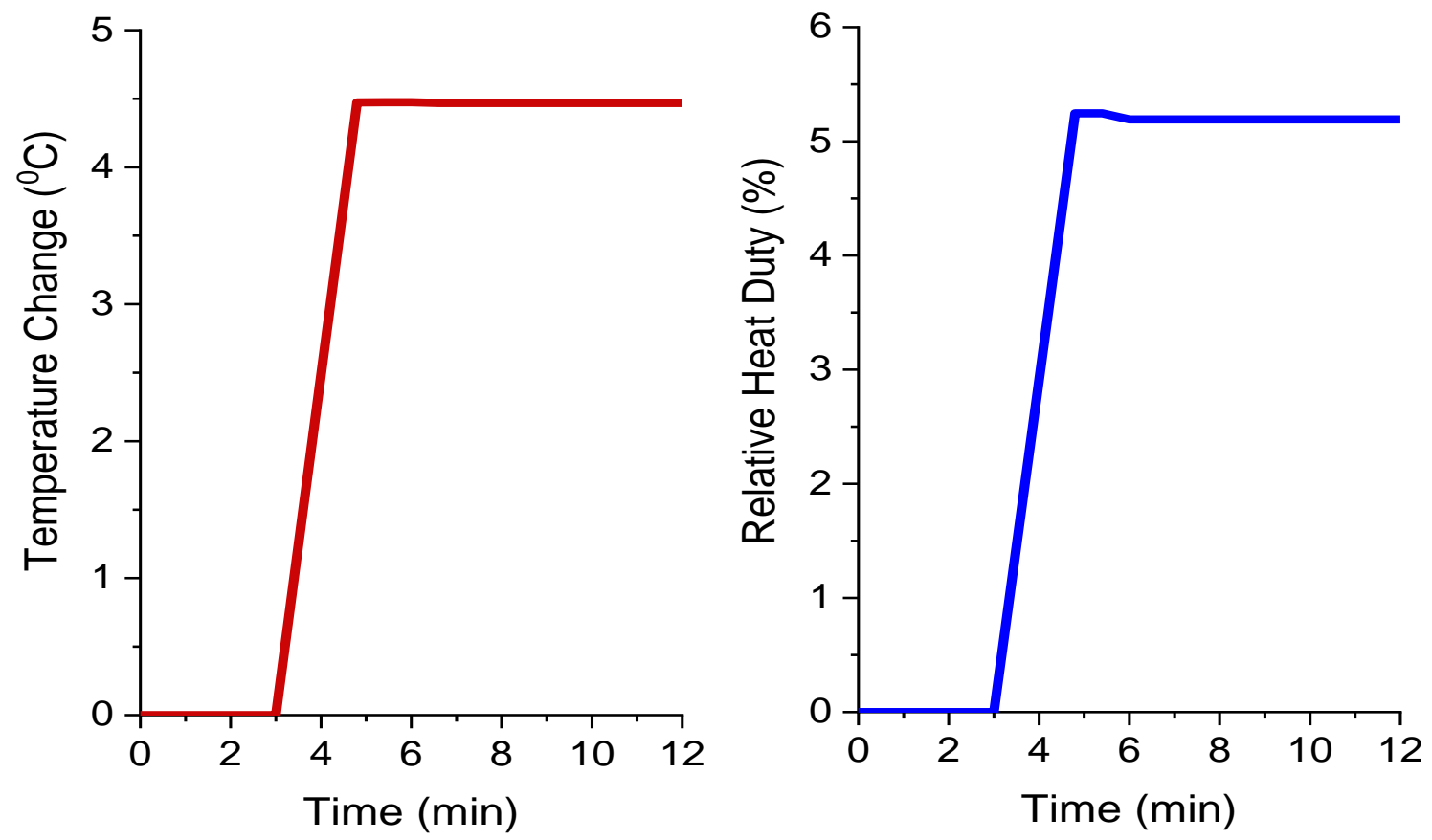

Figure 22. Effect of extraction steam temperature on cold side outlet temperature and heat duty 
Extraction steam pressure is step increased by 1 bar and its effects on extraction steam flowrate, cold side outlet temperature and heat duty are studied. Figures 23 and 24 show that the step results in $2.07 \%$ increase in the extraction stem flowrate, $0.53{ }^{\circ} \mathrm{C}$ rise in the cold side outlet temperature and $1.89 \%$ increase in the duty.

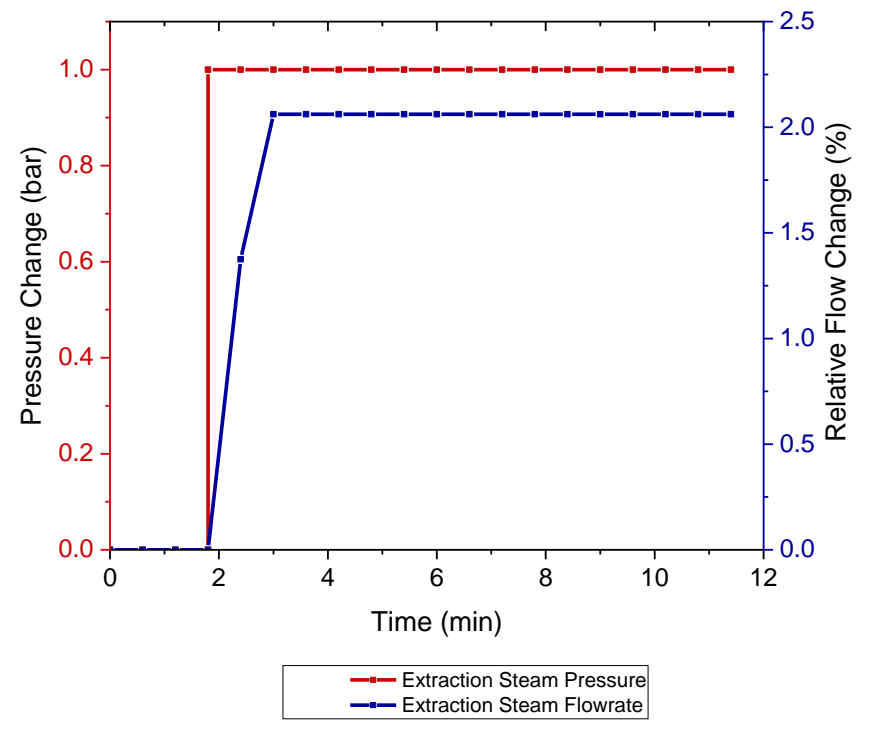

Figure 23. Effect of extraction steam pressure on extraction steam flowrate 

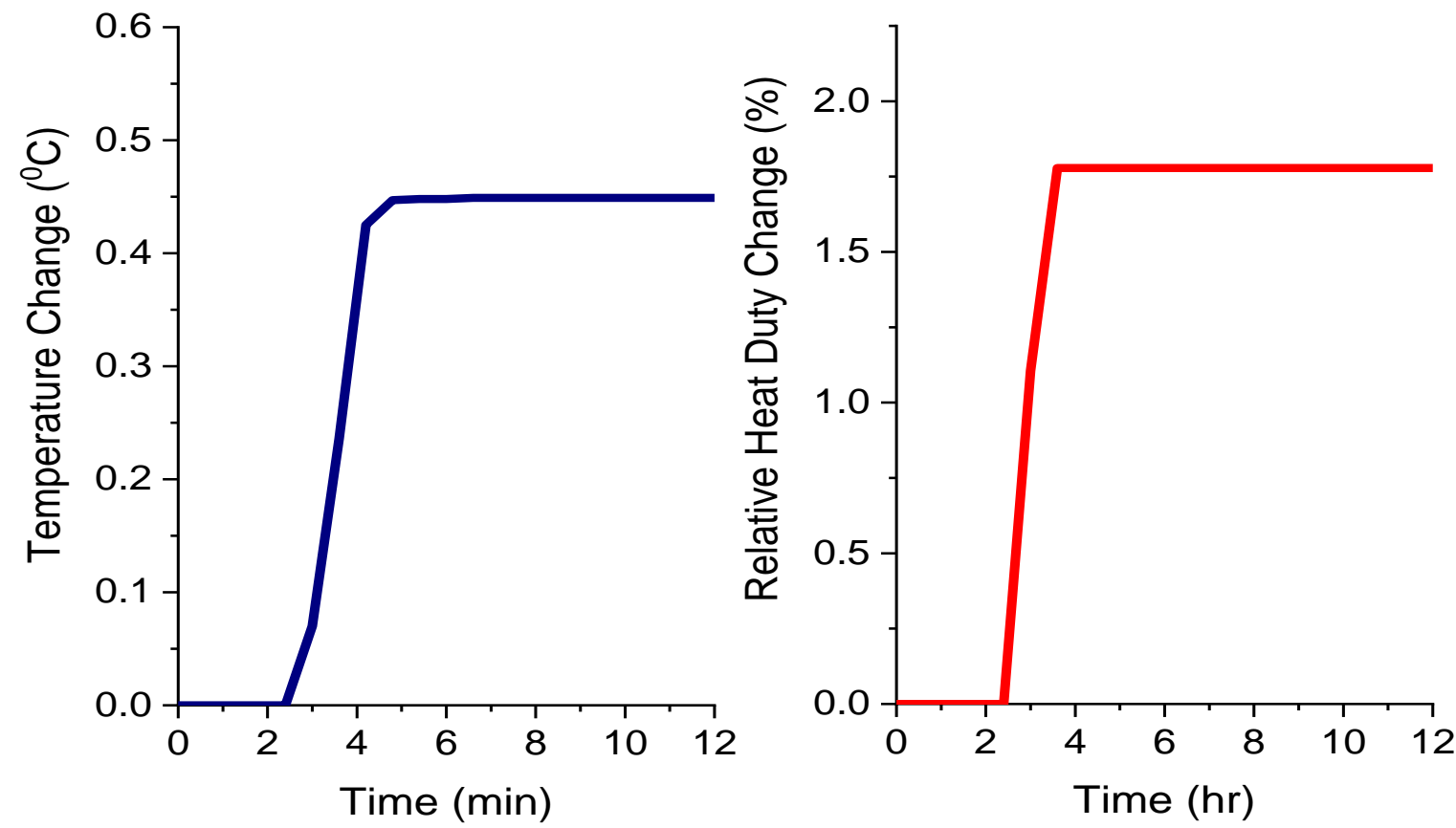

Figure 24. Effect of extraction steam pressure on cold side outlet temperature and heat duty 


\section{Investigation of tracking control and disturbance rejection performances:}

\section{Objective \#5: Investigation of tracking control and disturbance rejection performance}

With the integrated SCPC model developed, the studies were conducted for a load decrease from $100 \%$ to $40 \%$ over $20 \mathrm{~min}$, corresponding to a ramp rate of $3 \%$ load per min. This ramp rate is within an acceptable range of power industry ramp rates while maintaining all key operating variables within allowable deviations from their set points.

Figure 25 shows the response of the BFW flow rate and the main steam pressure to the ramp decrease initiated at $\mathrm{t}=1 \mathrm{hr}$. The $\mathrm{BFW}$ flowrate and main steam pressure decrease by approximately $63 \%$ and $62 \%$, respectively. These responses are hardly affected by the main steam temperature control figurations. The main steam pressure slides from 242 bar to 93 bar, corresponding to a ramp rate of 7.5 bar per min.

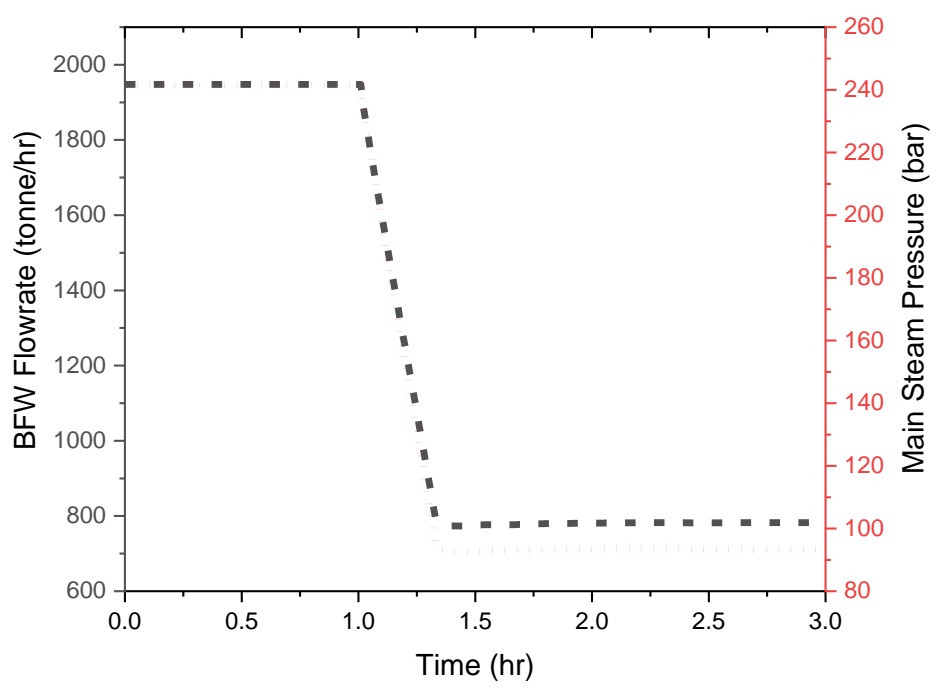

Figure 25. Response of BFW Flowrate and Main Steam Pressure to a 60\% Reduction in Load

Figure 26 depicts the response of main steam temperature to the $60 \%$ reduction in load for each of the control configurations detailed in Chapter 4. Both Configurations 1 and 3 leads to main steam temperatures that are well within the band; however, Configuration 2 results in a large 
undershoot that is unacceptable because of the boiler efficiency losses, ST efficiency losses, added thermal stresses on the reheater, and added condensation in the trailing LP stages, leading to damage to the ST. Configuration 3 provides the best control performance, limiting the maximum deviation in the main steam temperature to about $7^{\circ} \mathrm{C}$ and resulting in a settling time of about 15 min following the end of the ramp down in load.

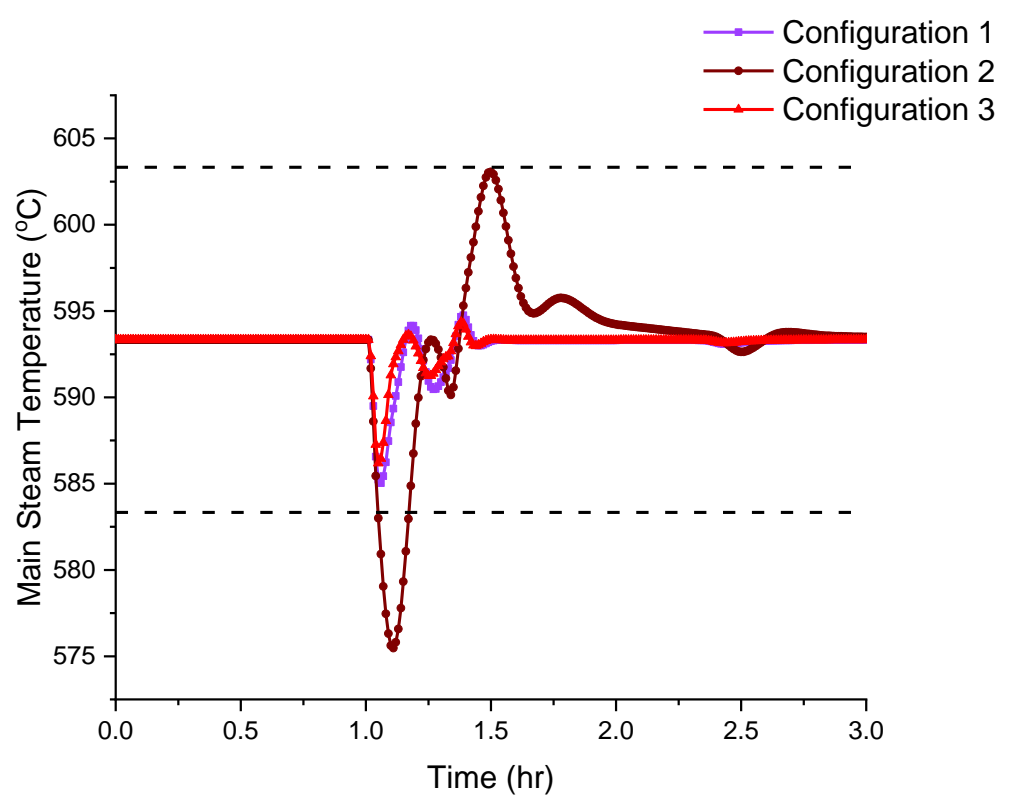

Figure 26. Transients of Main Steam Temperature for Different Control Strategies (the dotted lines shows $\mathrm{a}+/-10^{\circ} \mathrm{C}$ difference from the setpoint)

As discussed earlier, main steam temperature is maintained using BFW attemperation. Attemperator 2 is manipulated variable for main steam temperature control. Figure 27 represents transients of Attemperator 2 flowrate during load following to maintain main steam temperature for Configuration 3. 


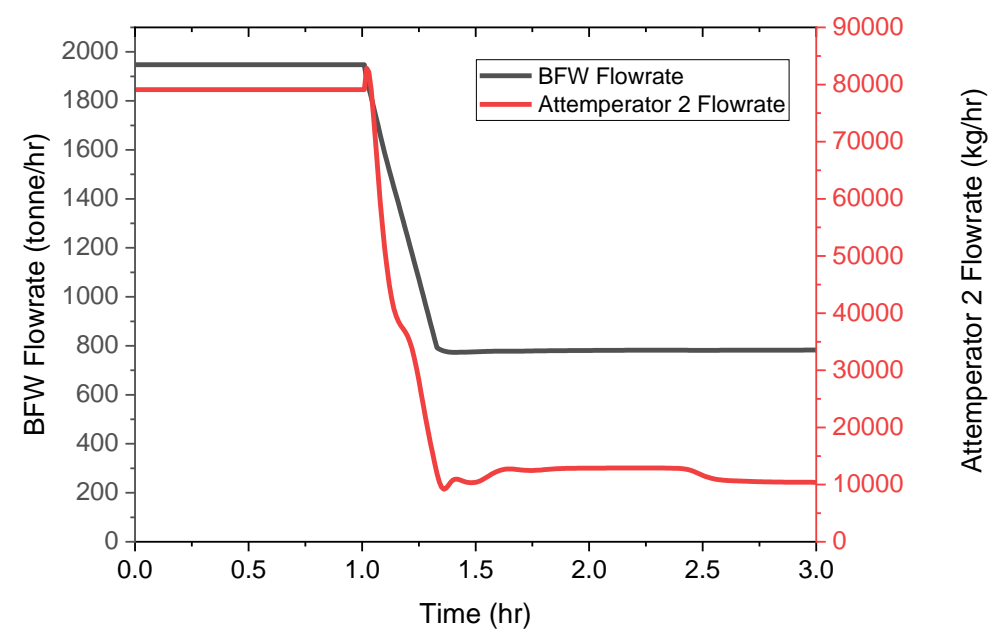

Figure 27. Transients of Attemperator 2 flowrate for Configuration 3.

Figure 28 shows the response of the dual control strategy to control the temperature of the reheated steam returning to the IP turbine. It should be noted that deviations in the main steam temperature can also affect the reheat steam temperature and therefore three configurations considered for controlling the main steam temperature can also have impact on the reheat stem temperature. Figure 28 shows the results. It can be seen here that the reheat temperature could be brought back to the original set point by each of the configurations considered. Though Configuration 3 has slightly higher overshoot than Configurations 1 and 2, it has faster settling time and lower oscillation. The performance of Configuration 1 is found to be the worst. However, the performance of each configuration is acceptable for controlling the reheat steam temperature. 


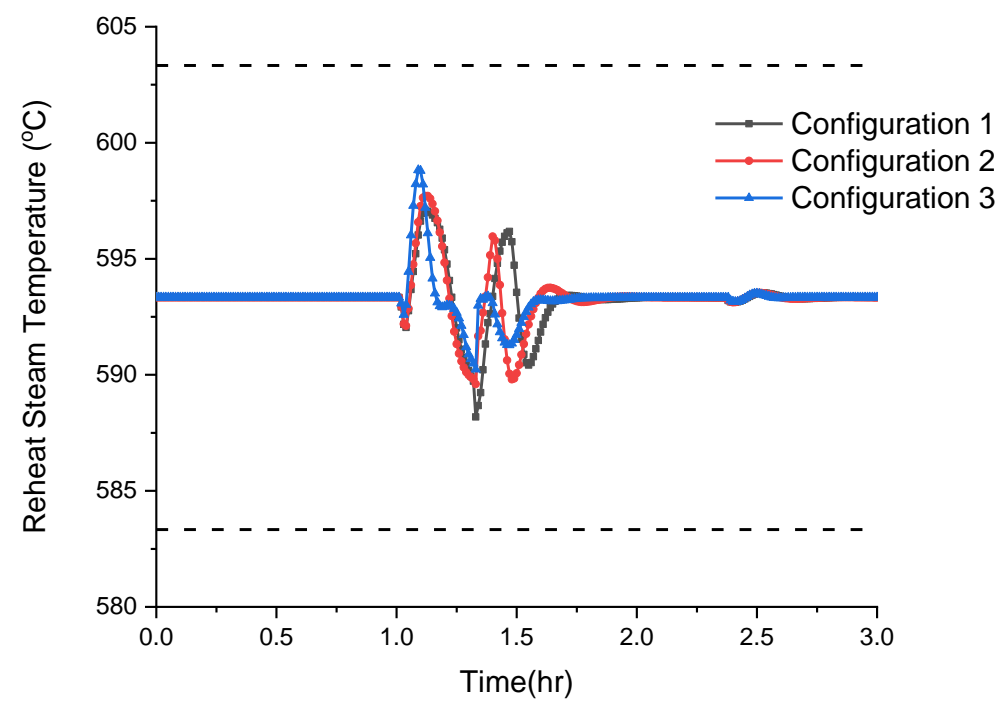

Figure 28. Response of Reheat Temperature for Different Control Strategies (the dotted lines show $\mathrm{a}+/-10^{\circ} \mathrm{C}$ difference from the setpoint)

As discussed earlier, reheat steam temperature is maintained using dual control strategy where primary control on reheat steam temperature is achieved using damper control. Figure 29 shows transient of fluegas to reheater during load following to maintain the reheat steam temperature. It should be noted that the total fluegas flowrate also decreases as the load decreases.

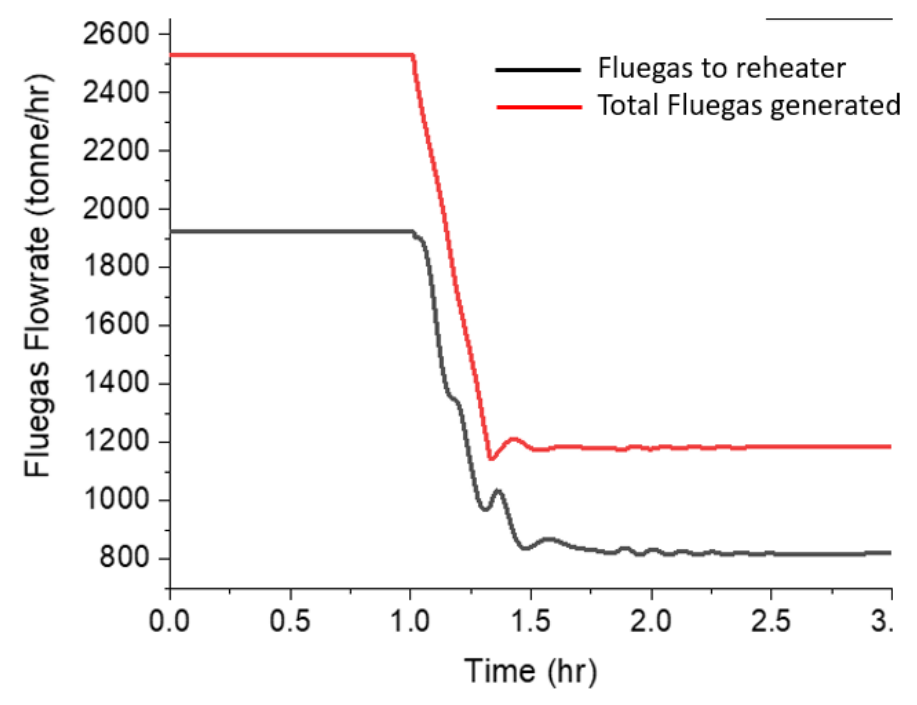

Figure 29. Transients in the Flue Gas Flowrate for Reheat Steam Temperature Control 
Figure 30 shows how the oxygen concentration in the boiler flue gas outlet responds to the $60 \%$ ramp decrease in load. Here again, the configuration used for main steam temperature control has no effect on the response of the oxygen concentration so only one plot is shown.

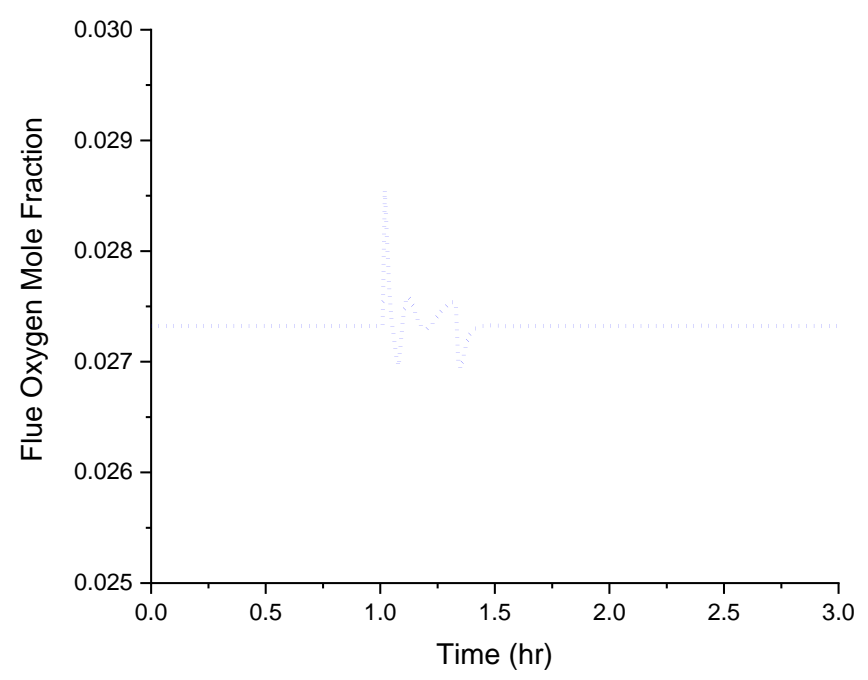

Figure 30. Response of the Boiler Outlet Oxygen Mole Fraction to a 60\% Reduction in Load

\section{Disturbance Rejection Studies:}

The composition of coal fed to a power plant can change considerably. The CCS should be designed for rejecting this disturbance efficiently while maintaining a set load. The base case composition of Illinois No. 6 coal is changed as shown in Table 8 for this transient study, corresponding to $2.59 \%$ reduction in the calorific value of the coal feed. This change is similar to the expected deviations in coal composition, even when considering coal of a similar grade or from the same mine. Here, it can be observed that the calorific value of the coal can deviate over a range of feeds, a disturbance that the CCS must be able to handle.

Table 8. Comparison of Coal Compositions for Disturbance Rejection Study.

\begin{tabular}{ccc}
\hline \multicolumn{3}{c}{ Ultimate Coal Analysis } \\
\hline & Base Case & Changed \\
$\mathrm{H}_{2} \mathrm{O}$ & 11.12 & 13.18 \\
\hline
\end{tabular}




\begin{tabular}{ccc}
\hline $\mathrm{C}$ & 63.75 & 59.36 \\
$\mathrm{H}_{2}$ & 4.5 & 5.18 \\
$\mathrm{~N}_{2}$ & 1.25 & 1.49 \\
$\mathrm{Cl}$ & 0.29 & 0.29 \\
$\mathrm{~S}$ & 2.51 & 2.88 \\
$\mathrm{O}_{2}$ & 6.88 & 7.92 \\
Ash & 9.7 & 9.7 \\
\hline
\end{tabular}

Figure 31 shows the transients in load and coal flow for the change in coal feed composition at time equal to $1 \mathrm{~h}$. Here, because of the lower calorific value of the new coal, the load drops by approximately $0.4 \%$, leading to an increase in the coal feed to compensate. The results are only shown here for using Configuration 3 to control the main steam and reheat steam temperatures, given similarities across the results for the three control configurations.

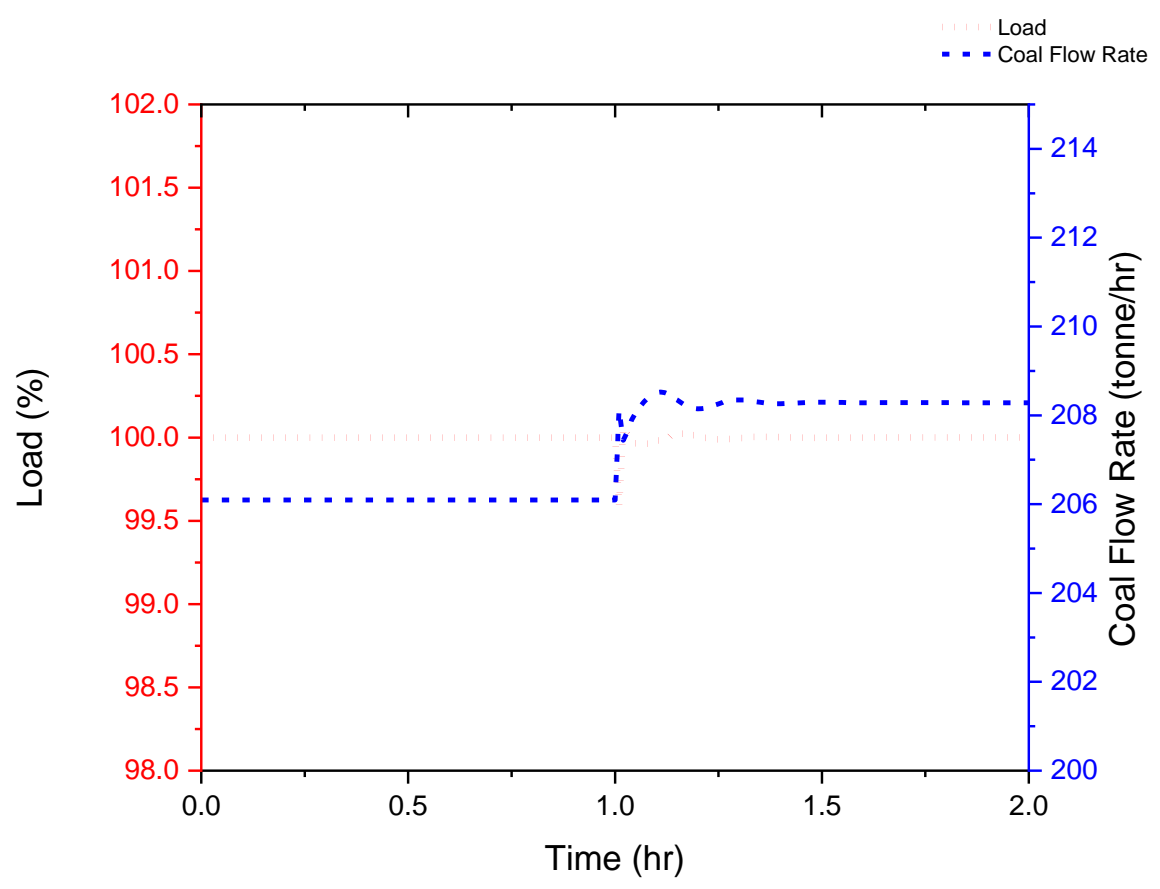

Figure 31 Disturbance Rejection Results for Load and Coal Flow 
Figure 32 shows the transients in the main steam temperature in response to the disturbance in coal composition. It is observed that Configuration 2 has lower undershoot (about $8^{\circ} \mathrm{C}$ ) than Configuration 1 but has higher overshoot than Configuration 1 (about $5^{\circ} \mathrm{C}$ ). Configuration 3 results in considerably lower under/overshoot with a maximum deviation of about $5^{\circ} \mathrm{C}$. Configuration 3 also results in a settling time that is more than $20 \mathrm{~min}$ faster compared to other configurations.

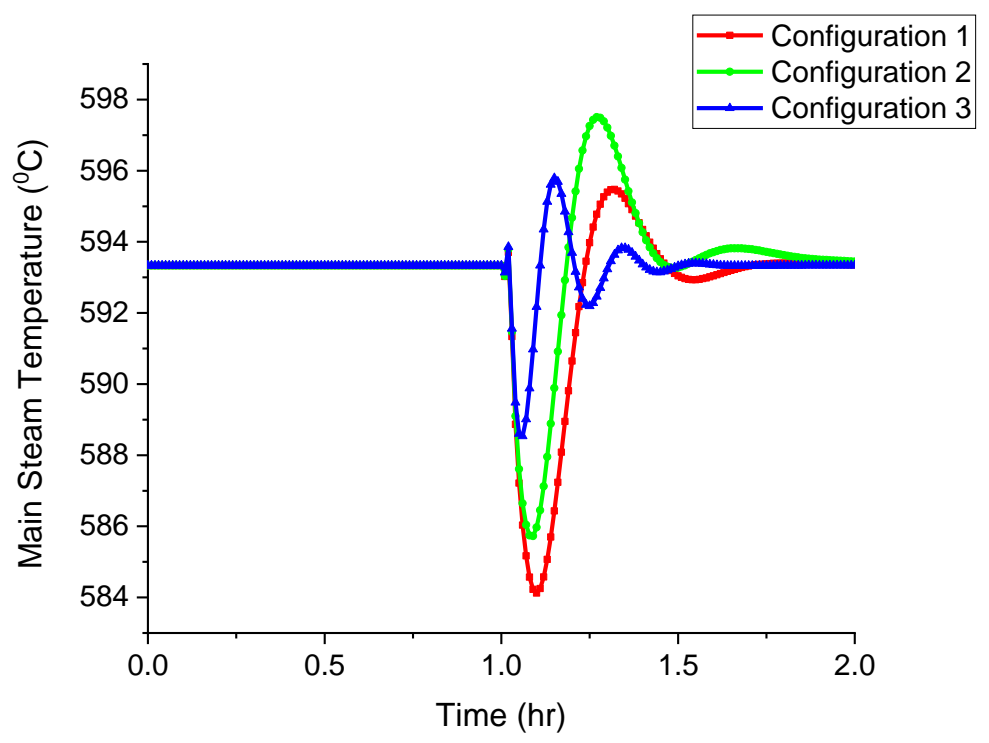

Figure 32. Disturbance Rejection Results for Main Steam Temperature

Figure 33 shows the transients in the oxygen concentration. It can be seen that the oxygen concentration in fluegas is maintained within 5\% deviation. Figure 34 shows the response of FD fan air flowrate to maintain the oxygen concentration in the exiting fluegas. 


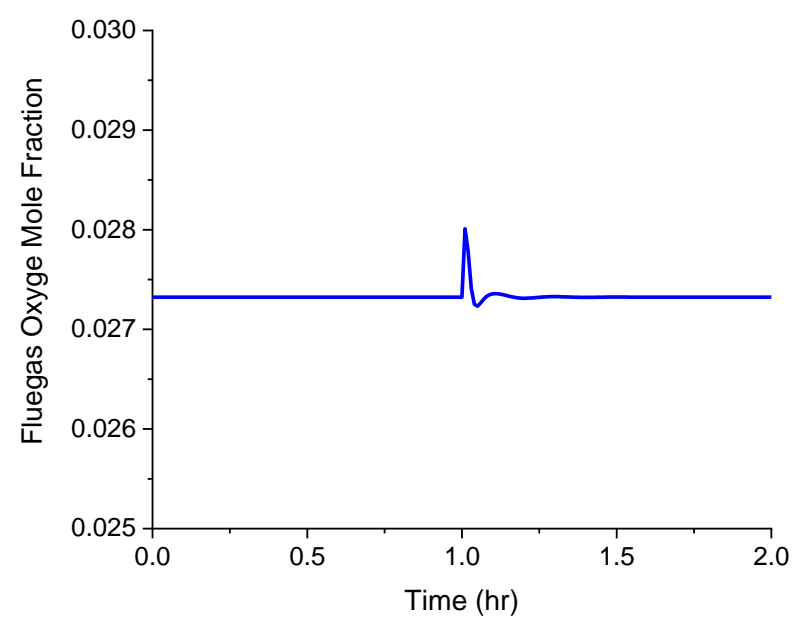

Figure 33. Disturbance Rejection Results for Oxygen Concentration

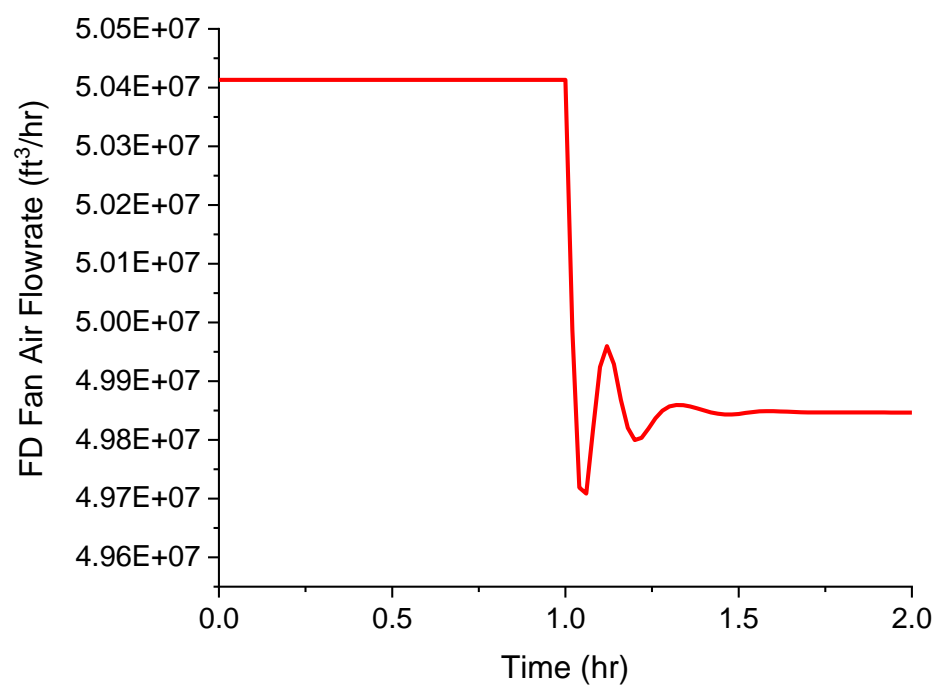

Figure 34. Response of FD Fan Air Flowrate to maintain Oxygen Concentration

Considering both servo control and disturbance rejection performance, it can be observed that Configuration 3 is superior to Configuration 1 and 2. 


\section{Conclusion and Future Work:}

\section{Conclusion:}

A plant-wide dynamic model of a supercritical pulverized coal power plant with $\mathrm{CO}_{2}$ capture is developed in this work. A coordinated control strategy is designed and its performance is studied for both disturbance rejection and servo control. Sliding-pressure operation is considered while ramping down the load from $100 \%$ to $40 \%$ at a ramp rate of $3 \%$ load per min. As the final and reheat steam temperatures must be controlled tightly, performance of three control configurations is evaluated. For final steam temperature control, Configuration 3 that includes the Smith Predictor for handling time delays on the water/steam-side results in maximum deviation of about $7^{\circ} \mathrm{C}$ in the final steam temperature and a settling time of about $15 \mathrm{~min}$ following the end of the ramp change. Configuration 1 also provides similar control performance. However, Configuration 2 results in a much poorer tracking control performance with the maximum deviation of about $18^{\circ} \mathrm{C}$ in the final steam temperature and much longer settling time. For the reheat temperature control, Configuration 3 has the best performance and Configuration 1 has the worst performance while performances of all three configurations are acceptable.

Performance of the control system is evaluated for a disturbance in the coal feed composition. The $2.59 \%$ reduction in the calorific value of the coal feed could be rejected very efficiently by the coordinated control strategy. Maximum deviation in the load is found to be about $0.4 \%$. Maximum deviation in the final steam temperature is found to be about $9^{\circ} \mathrm{C}, 8^{\circ} \mathrm{C}$, and $5^{\circ} \mathrm{C}$ for Configuration 1, Configuration 2, Configuration 3, respectively. Settling time of Configuration 3 is found to be faster by more than $20 \mathrm{~min}$ in comparison to the other configurations. It should be noted that no feedforward input is considered for this disturbance. Overall, Configuration 3 with the Smith Predictor is found to provide the best performance for main and reheat steam temperature control for both tracking and disturbance rejection problems.

A custom model is developed for the FWH in ACM. The model takes into account complicated interactions involving operation of FWH during load following and especially under sliding pressure operation. The model can calculate the dynamic change in the size of the three zones due to changing operating conditions. This feedwater heater model is validated using the design data from IPP. 


\section{Future Work:}

In continuation of this work, following things can be focused for future work:

The FWH modelled developed in ACM can be integrated with plant wide SCPC model to investigate load following. With custom FWH blocks as a part of integrated flowsheet, the effect of liquid level on plant heat rate at full load and part load operation can be evaluated. The proposed CCS can be updated with the inclusion of control strategies with respect to feedwater heater operation.

Similarly, advanced control strategies like MPC can be developed to improve performance of SCPC plants under load following and part load operation. 


\section{Publications and Presentation:}

This work has resulted in the following published journal paper:

Sarda, P., Hedrick, E., Reynolds, K., Bhattacharyya, D., Zitney, S.E., and Omell, B., "Development of a Dynamic Model and Control System for Load-Following Studies of the Supercritical Pulverized Coal Power Plants," Processes 2018, 6, 226.

This work has resulted in the following submitted manuscript:

Hedrick, E., Reynolds, K., Sarda, P., Bhattacharyya, D., Zitney, S.E., and Omell, B., 'Development of a Reinforcement Learning-Based Control Strategy for Load Following in Supercritical Pulverized Coal (SCPC) Power Plants' Clean Energy Conference in Clearwater, FL 16-21 June 2019.

This work has resulted in the following presentations:

- Hedrick, E., Reynolds, K., Sarda, P., Bhattacharyya, D., Zitney, S.E., and Omell, B., 'Development of a Reinforcement Learning-Based Control Strategy for Load Following in Supercritical Pulverized Coal (SCPC) Power Plants' presented at Clean Energy Conference in Clearwater, FL 16-21 June 2019.

- K. Reynolds, E. Hedrick, P. Sarda, S. E. Zitney, B. Omell, and D. Bhattacharyya, "Dynamic Modeling and Simulation of a Supercritical Pulverized Coal-Fired Boiler Under Load-Following Conditions," presented at the EPRI Flexible Operation Conference, Pittsburgh, PA, USA, 06-Jun-2019.

- Sarda P, Hedrick E, Reynolds K, Tomer E, Omell B P, Zitney S E, Bhattacharyya D, "Development of Advanced Model-Based Controllers for Optimal Load-Following Operation of the Supercritical Pulverized Caol Power Plants", Paper 184w, AIChE Annual Meeting, Pittsburgh, PA, October 28-November 2, 2018

- Sarda P., E. Hedrick, K. Reynolds, E. Tomer, A.P. Burgard, A. Lee, J.C. Eslick, D.C. Miller, B. Omell, S.E. Zitney*, and D. Bhattacharyya, "Optimal Load-Following Operation of Supercritical Pulverized Coal Power Plants," EPRI Flexible Operations Conference: Conventional and Combined Cycle Power Plant Cycling Damage and Management, Tulsa, OK, June 6-8 


\section{Notations:}

Table 9 describes all the notations used in this section.

Table 9. Notation used in FWH Modelling.

\begin{tabular}{|c|c|}
\hline Symbol & Description \\
\hline$\rho_{\mathrm{c}}$ & Cold Fluid Density \\
\hline $\mathrm{v}_{\mathrm{c}}$ & Cold Fluid Velocity \\
\hline $\mathrm{h}_{\mathrm{c}}$ & Cold Fluid Enthalpy \\
\hline Pc & Cold Fluid Pressure \\
\hline $\mathrm{q}_{\text {wal,c }}$ & Heat Flux per unit volume for cold side \\
\hline $\mathrm{T}_{\mathrm{c}}$ & Cold Fluid temperature \\
\hline $\mathrm{v}_{\mathrm{hv}}$ & Hot Fluid Vapor Velocity \\
\hline$\rho_{\mathrm{hv}}$ & Hot Fluid Vapor Density \\
\hline $\mathrm{m}_{\text {cond }}^{\cdot}$ & Condensate per unit volume \\
\hline $\mathrm{h}_{\mathrm{hv}}$ & Hot Fluid Vapor Enthalpy \\
\hline $\mathrm{q}_{\text {wal,h }}$ & Heat Flux per unit volume for hot side \\
\hline hsat, liq & Saturated Liquid Enthalpy for hot fluid \\
\hline $\mathrm{P}_{\mathrm{h}}$ & Shell Side Pressure \\
\hline $\mathrm{T}_{\mathrm{h}}$ & Hot Fluid Temperature \\
\hline $\mathrm{T}_{\mathrm{h}, \mathrm{sat}}$ & Saturated Temperature of Hot Fluid \\
\hline$\rho_{\mathrm{hl}}$ & Hot Fluid liquid Density \\
\hline $\mathrm{v}_{\mathrm{hl}}$ & Hot Fluid Liquid Velocity \\
\hline $\mathrm{h}_{\mathrm{hl}}$ & Hot Fluid Liquid Enthalpy \\
\hline $\mathrm{V}_{\text {Shell }}$ & Effective Volume of Shell \\
\hline$\dot{\mathrm{m}}_{\mathrm{h}, \mathrm{v}, \mathrm{in}}$ & Extraction Steam Inlet Flowrate \\
\hline
\end{tabular}




\begin{tabular}{|c|c|}
\hline$\dot{\mathrm{m}}_{\text {cond,total }}$ & Total Steam Condensate In Shell \\
\hline ID & Inner Diameter of Tube \\
\hline OD & Outer Diameter of Tube \\
\hline $\mathrm{Nt}$ & Number of Tubes \\
\hline $\mathrm{Lt}$ & Length of Tube \\
\hline $\mathrm{H}_{\mathrm{s}}$ & Height of Shell \\
\hline $\mathrm{W}_{\mathrm{s}}$ & Width of Shell \\
\hline $\mathrm{s}_{1}$ & Transverse Pitch \\
\hline $\mathrm{s}_{2}$ & Longitudinal Pitch \\
\hline A & Transverse Pitch Ratio \\
\hline B & Longitudinal Pitch Ratio \\
\hline$\Psi$ & Void fraction \\
\hline $\mathrm{L}_{\text {char }}$ & Streamed Length of Tube \\
\hline $\mathrm{f}_{\mathrm{A}, \mathrm{in}-\mathrm{line}}$ & Factor for Staggered Tube Arrangement \\
\hline$C_{p, c}$ & Specific heat of Cold Fluid \\
\hline$u_{c}$ & Viscosity of Cold Fluid \\
\hline $\mathrm{k}_{\mathrm{c}}$ & Conductivity of Cold Fluid \\
\hline $\operatorname{Re}_{\mathrm{c}}$ & Reynolds Number of Cold Side \\
\hline $\operatorname{Pr}_{c}$ & Pradalts Number for Cold Side \\
\hline$\xi_{\mathrm{c}}$ & Frictional Coefficient for Cold Side \\
\hline $\mathrm{Nu}_{\mathrm{c}}$ & Nusselts Number for Cold Side \\
\hline $\mathrm{h}_{\mathrm{c}}$ & Cold Side Heat Transfer Coefficient \\
\hline$C_{p, h v}$ & Specific heat of Hot Fluid (Vapor) \\
\hline
\end{tabular}




\begin{tabular}{|c|c|}
\hline$\mu_{\mathrm{hv}}$ & Viscosity of Hot Fluid (Vapor) \\
\hline $\mathrm{k}_{\mathrm{hv}}$ & Conductivity of Hot Fluid (Vapor) \\
\hline $\operatorname{Re}_{\mathrm{hv}}$ & Reynolds Number Hot Side (Desuperheating) \\
\hline $\operatorname{Pr}_{\mathrm{hv}}$ & Prandalts Number Hot Side (Desuperheating) \\
\hline $\mathrm{Nu}_{\text {turb,hv }}$ & Turbulent Nusselts Number Hot Side (Desuperheating) \\
\hline $\mathrm{Nu}_{\text {lam,hv }}$ & Laminar Nusselts Number Hot Side (Desuperheating) \\
\hline $\mathrm{Nu}_{\text {tube,hv }}$ & Tube Nusselts Number Hot Side (Desuperheating) \\
\hline $\mathrm{Nu}_{\text {bundle,hv }}$ & Tube Bundle Nusselts Number Hot Side (Desuperheating) \\
\hline $\mathrm{C}_{\mathrm{p}, \mathrm{hl}}$ & Specific heat of Hot Fluid (Liquid) \\
\hline$\mu_{\mathrm{hl}}$ & Viscosity of Hot Fluid (Liquid) \\
\hline $\mathrm{k}_{\mathrm{hl}}$ & Conductivity of Hot Fluid (Liquid) \\
\hline $\mathrm{Re}_{\mathrm{hl}}$ & Reynolds Number Hot Side (Subcooling) \\
\hline $\operatorname{Pr}_{\mathrm{hl}}$ & Prandalts Number Hot Side (Subcooling) \\
\hline $\mathrm{Nu}_{\text {turb,hl }}$ & Turbulent Nusselts Number Hot Side (Subcooling) \\
\hline $\mathrm{Nu}_{\mathrm{lam}, \mathrm{hl}}$ & Laminar Nusselts Number Hot Side (Subcooling) \\
\hline $\mathrm{Nu}_{\text {tube,hl }}$ & Tube Nusselts Number Hot Side (Subcooling) \\
\hline $\mathrm{Nu}_{\text {bundle,hl }}$ & Tube Bundle Nusselts Number Hot Side (Subcooling) \\
\hline $\mathrm{h}_{\mathrm{gr}}$ & Gravity Dominated HT Coefficient (Condensation) \\
\hline $\mathrm{h}_{\mathrm{sh}}$ & Shear Dominated HT Coefficient (Condensation) \\
\hline $\mathrm{h}_{\mathrm{ho}}$ & Nominal HT Coefficient (Condensation) \\
\hline $\mathrm{h}_{\mathrm{h}}$ & Hot Side Heat Transfer Coefficient \\
\hline $\mathrm{q}_{\mathrm{c}}$ & Heat Flux Per Unit Area for Cold Fluid \\
\hline $\mathrm{q}_{\mathrm{h}}$ & Heat Flux Per Unit Area for Hot Fluid \\
\hline
\end{tabular}




\begin{tabular}{|c|c|}
\hline $\mathrm{T}_{\mathrm{t}}$ & Tube Temperature \\
\hline$\rho_{\mathrm{t}}$ & Tube Material Density \\
\hline $\mathrm{C}_{\mathrm{p}, \mathrm{t}}$ & Tube Material Specific Heat \\
\hline $\mathrm{k}_{\text {tube }}$ & Tube Material Conductivity \\
\hline$\wedge$ & Latent heat of Vaporization \\
\hline
\end{tabular}




\section{Appendix:}

List of the controllers used as a part of regulatory layer developed for integrated SCPC dynamic model for case NETL B12B.

Single Loop Controller:

\begin{tabular}{|c|c|c|}
\hline Controller Name & Controlled Variable & Manipulated Variable \\
\hline $\begin{array}{l}\text { Infiltration Air Flow } \\
\text { Controller }\end{array}$ & Infiltration Air Flow & Control Valve Opening \\
\hline Water_FGD Controller & Water Flowrate to FGD & Control Valve Opening \\
\hline Air_FGD Controller & Air Flowrate to FGD & Compressor Power \\
\hline Hotwell Level Controller & Hotwell Level & Makeup Water Flowrate \\
\hline Deareator Level Controller & Deareator Level & $\begin{array}{l}\text { Condensate Pump Discharge } \\
\text { Flowrate }\end{array}$ \\
\hline Attemperator Controller & $\begin{array}{l}\text { Total Attemperation } \\
\text { Flowrate }\end{array}$ & Control Valve Opening \\
\hline FWH1_Drain Controller & $\begin{array}{l}\text { Drain Flowrate through } \\
\text { FWH1 }\end{array}$ & Control Valve Opening \\
\hline FWH2_Drain Controller & $\begin{array}{l}\text { Drain Flowrate through } \\
\text { FWH2 }\end{array}$ & Control Valve Opening \\
\hline FWH3_Drain Controller & $\begin{array}{l}\text { Drain Flowrate through } \\
\text { FWH3 }\end{array}$ & Control Valve Opening \\
\hline FWH5_Drain Controller & $\begin{array}{l}\text { Drain Flowrate through } \\
\text { FWH5 }\end{array}$ & Control Valve Opening \\
\hline FWH6_Drain Controller & $\begin{array}{l}\text { Drain Flowrate through } \\
\text { FWH6 }\end{array}$ & Control Valve Opening \\
\hline Extraction 4 Controller & $\begin{array}{l}\text { Dearator Overhead Steam } \\
\text { Flowrate }\end{array}$ & Control Valve Opening \\
\hline MEA_RB Controller & $\begin{array}{l}\text { Steam Flowrate to MEA } \\
\text { RB }\end{array}$ & Control Valve Opening \\
\hline
\end{tabular}




\begin{tabular}{|l|l|l|}
\hline DRYR_RB Controller & $\begin{array}{l}\text { Steam Flowrate to DRYR } \\
\text { RB }\end{array}$ & Control Valve Opening \\
\hline REC_RB Controller & Steam Flowrate to REC RB & Control Valve Opening \\
\hline $\begin{array}{l}\text { Economizer Temp } \\
\text { Controller }\end{array}$ & $\begin{array}{l}\text { Economizer Outlet Fluegas } \\
\text { Temperature }\end{array}$ & $\begin{array}{l}\text { Economizer Bypass Valve } \\
\text { Opening }\end{array}$ \\
\hline
\end{tabular}

Cascade Controller:

\begin{tabular}{|l|l|l|}
\hline Outer loop CV & Inner Loop CV & Manipulated Variable \\
\hline BFW Turbine Power & Extraction Steam to BFW Turbine & Control Valve Opening \\
\hline FWH 6 Outlet Temperature & Extraction Steam to FWH 6 & Control Valve Opening \\
\hline FWH 5 Outlet Temperature & Extraction Steam to FWH 5 & Control Valve Opening \\
\hline FWH 3 Outlet Temperature & Extraction Steam to FWH 3 & Control Valve Opening \\
\hline FWH 2 Outlet Temperature & Extraction Steam to FWH 2 & Control Valve Opening \\
\hline FWH 1 Outlet Temperature & Extraction Steam to FWH 1 & Control Valve Opening \\
\hline CaCO $/$ SO ${ }_{2}$ ratio to FGD & Lime Flowrate to FGD & Control Valve Opening \\
\hline Air Flow through FD Fan & Shaft Speed for FD Fan & Power to FD Fan \\
\hline Air Flow through PA Fan & Shaft Speed for PA Fan & Power to PA Fan \\
\hline $\begin{array}{l}\text { Attemperator 2 Valve } \\
\text { Opening }\end{array}$ & Attemperator 1 Spray Flowrate & Control Valve Opening \\
\hline Final Steam Temperature & Attemperator 2 Spray Flowrate & Control Valve Opening \\
\hline $\begin{array}{l}\text { Reheater Outlet Steam } \\
\text { Temperature 1 }\end{array}$ & Fluegas Flow Through Reheater & Damper Positioning \\
\hline $\begin{array}{l}\text { Reheater Outlet Steam } \\
\text { Temperature 2 }\end{array}$ & Attemperator 3 Spray Flowrate & Control Valve Opening \\
\hline Plant Load & Coal Flow & Control Valve Opening \\
\hline
\end{tabular}




\section{References:}

Almedilla, J. R.; Pabilona, L. L.; Villanueva, E. P. Performance Evaluation and Off Design Analysis of the HP and LP Feed Water Heaters on a $3 \times 135$ MW Coal Fired Power Plant. Journal of Applied Mechanical Engineering 2018, 7, 1-14, doi:10.4172/2168-9873.1000308.

Alobaid, F.; Mertens, N.; Starkloff, R.; Lanz, T.; Heinze, C.; Epple, B. Progress in dynamic simulation of thermal power plants. Prog. Energy Combust. Sci. 2017, 59, 79-162, doi:10.1016/j.pecs.2016.11.001.

Aspen Exchanger Design \& Rating. Available online: https://www.aspentech.com/en/products/engineering/aspen-exchanger-design-and-rating (accessed on 1 January 2018).

Deng, K.; Yang, C.; Chen, H.; Zhou, N.; Huang, S. Start-Up and dynamic processes simulation of supercritical once-through boiler. Applied Thermal Engineering 2017, 115, 937-946, doi:10.1016/j.applthermaleng.2017.01.016.

Devandiran, E.; Shaisundaram, V. S.; Ganesh, P. S.; Vivek, S. Influence of Feed Water Heaters on the Performance of Coal Fired Power Plants. International Journal of Latest Technology in Engineering, Management \& Applied Science 2016, 5, 115-119.

Dong, L.; Ming, Z.; Yong-jun, L.; Ru-jia, S. Discussion of Ultra-Supercritical Units Feed Water Control Strategy. Procedia Eng. 2011, 15, 828-833, doi:10.1016/j.proeng.2011.08.154

Draganescu, M.; Guo, S.; Wojcik, J.; Wang, J.; Liu, X.; Hou, G.; Xue, Y.; Gao, Q. Generalized Predictive Control for superheated steam temperature regulation in a supercritical coal-fired power plant. CSEE J. Power Energy Syst. 2015, 1, 69-77, doi:10.17775/CSEEJPES.2015.00009.

D. P. Hanak, C. Biliyok, and V. Manovic, "Evaluation and Modeling of Part-Load Performance of Coal-Fired Power Plant with Postcombustion CO2 Capture," Energy \& Fuels, vol. 29, no. 6, pp. 3833-3844, 2015/06/18 2015.

Espatolero, S.; Romeo, L. M.; Cortés, C. Efficiency improvement strategies for the feedwater heaters network designing in supercritical coal-fired power plants. Applied Thermal Engineering 2014, 73, 449-460, doi:10.1016/j.applthermaleng.2014.08.011.

Fout, T.;Zoelle, A.; Keairns, D.; Pinkerton, L.L.; Turner, M.J.; Woods, M.; Kuehn, N.; Shah, V.; Chou, V. Cost and Performance Baseline for Fossil Energy Plants Volume la: Bituminous Coal (PC) and Natural Gas to Electricity; Technical Report; U.S. Department of Energy: Pittsburgh, PA, USA, July 2015. 
Hentschel, J.; Zindler, H.; Spliethoff, H. Modelling and transient simulation of a supercritical coalfired power plant: Dynamic response to extended secondary control power output. Energy 2017, 137, 927-940, doi:10.1016/j.energy.2017.02.165.

He, Fernando V. Lima, "Development and implementation of advanced control strategies for power plant cycling with carbon capture", Computers \& Chemical Engineering, Volume 121,2019, Pages 497-509.

J. Saari, J. Kaikko, E. Vakkilainen, and S. Savolainen, "Comparison of power plant steam condenser heat transfer models for on-line condition monitoring," Applied Thermal Engineering, vol. 62, no. 1, pp. 37-47, Jan. 2014.

Liese, E. Modeling of a Steam Turbine Including Partial Arc Admission for Use in a Process Simulation Software Environment. J. Eng. Gas Turbines Power 2014, 136, 112605, doi:10.1115/1.4027255.

Madron, Frantisek. (2013). Modeling a 3-zone Feedwater Heater. 10.13140/RG.2.1.3664.7849.

Ogunnaike, B.A.; Ray, H.W. Process Dynamics, Modeling and Control; Oxford University Press: Oxford, United Kingdom, 1994.

Sarda, P.; Hedrick, E.; Reynolds, K.; Bhattacharyya, D.; Zitney, S.E.; Omell, B. Development of a Dynamic Model and Control System for Load-Following Studies of Supercritical Pulverized Coal Power Plants. Processes 2018, 6, 226.

Shu, Z.; Zixue, L.; Yanxiang, D.; Huaichun, Z. Development of a distributed-parameter model for the evaporation system in a supercritical W-shaped boiler. Applied Thermal Engineering 2014, 62, 123-132, doi:10.1016/j.applthermaleng.2013.09.029.

Shulka, A. 660 MW Supercritical Boiler. Available online: https://www.slideshare.net/AshvaniShukla/660-mw-supercritical-boiler (accessed on 21 June 2018).

Starkloff, R.; Alobaid, F.; Karner, K.; Epple, B.; Schmitz, M.; Boehm, F. Development and validation of a dynamic simulation model for a large coal-fired power plant. Appl. Therm. Eng. 2015, 91, 496-506, doi:10.1016/j.applthermaleng.2015.08.015.

The Basics of Fan Performance Tables, Fan Curves, System Resistance Curves and Fan Laws (FA/100-99). Available online: http://www.greenheck.com/library/articles/10 (accessed on 1 January 2017).

Turton, R.; Bailie, R.C.; Whiting, W.B.; Shaeiwitz, J.A.; Bhattacharyya, D. Analysis, Synthesis, and Design of Chemical Processes; Prentice Hall International Series in the Physical and Chemical Engineering Sciences; 4th ed.; Prentice Hall: Upper Saddle River, NJ, USA, 2012; ISBN 978-0-13-261812-0.

VDI Heat Atlas, Second Edition. Berlin Heidelburg: Springer-Verlag, 2010. 
Wang, J.; Zhang, Y.; Li, Y.; Huang, S. A non-equal fragment model of a water-wall in a supercritical boiler. J. Energy Inst. 2015, 88, 143-150, doi:10.1016/j.joei.2014.05.004.

Wang, C.; Liu, M.; Li, B.; Liu, Y.; Yan, J. Thermodynamic analysis on the transient cycling of coal-fired power plants: Simulation study of a 660 MW supercritical unit. Energy 2017, 122, 505-527, doi:10.1016/j.energy.2017.01.123. 